\title{
EXPLORING THE USE OF SOCIAL COMPARISON BY INDIVIDUALS RECOVERING FROM TRAUMATIC BRAIN INJURY.
}

\section{DISSERTATION}

\author{
Presented in Partial Fulfillment of the Requirements for \\ the Degree Doctor of Philosophy in the \\ Graduate School of the Ohio State University
}

By

Patricia McSweeney Arenth, M.A.

$* * * * *$

The Ohio State University

2003

Dissertation Committee:

Approved By

Dr. Lyle D. Schmidt, Co-Adviser

Dr. John D. Corrigan, Co-Adviser

Dr. W. Bruce Walsh

Co-Advisers

Department of Psychology 



\begin{abstract}
This study explores the use of social comparison by individuals who have sustained traumatic brain injuries (TBI) as part of the process of recovery and adjustment within the first year following injury. Two separate groups of participants were studied: The first group was surveyed within one month of discharge from treatment at an inpatient Traumatic Brain Injury (TBI) Unit at a large mid-western university medical center. The second group was surveyed at approximately 6 months post-discharge from the same facility. Groups were compared based on their responses to instruments measuring physical and mental health, need for comparison, subjective well-being (composed of satisfaction with life and positive and negative affectivity), and level of disability. Questions regarding support group participation were compared between groups. Subjects' ratings of themselves as compared to others with TBI, as well as recollections of their physicians' predictions of recovery were also assessed.

Correlations from the present study were also compared with those presented in a model by VanderZee, Buunk, DeRuiter, Tempelar, VanSonderen \& Sanderman (1996) which evaluated social comparison activity by individuals diagnosed with cancer. Results of the current study suggested that, despite significant levels of disability, individuals with TBI may make use of social comparison activity to maintain subjective well-being with some success, at least early in recovery. It appears that there may be factors that reduce the effectiveness of social comparison
\end{abstract}


activity as time post injury progresses. Significant differences were not found between groups in terms of direction of comparison, however participants reported the use of downward comparison activity resulting in a positive affective response most frequently. Possible mediating factors, as well as implications for adjustment and support group participation are discussed. Findings suggested a fair match between the current study and the model presented by VanderZee et al. (1996). Possible reasons for the differences are discussed.

Limitations of this study included sample size and possible demographic variables affected by setting and geography. Further assessment of cognitive issues related to brain injury (i.e. lack of awareness of deficits, limitations in abstract reasoning or memory) may need to be examined more fully in relation to social comparison activity. In addition, future longitudinal studies looking even further post-injury may help to clarify some of the issues related to how social comparison activity may change over time as compared to the current cross sectional design. Further evaluation of other factors, such as mood, level of adjustment, and purpose of comparison may also help to clarify how social comparison activity is utilized by individuals with traumatic brain injury. 
To John and Keenan with love and appreciation

And

In memory of my mother,

Margaret A. McSweeney

March 18, 1940 - July 29, 1998 


\section{ACKNOWLEDGMENTS}

I would like to express sincere appreciation to my Co-Advisers, Dr. Lyle Schmidt and Dr. John Corrigan. I have felt fortunate to have the expertise and perspective of two advisers throughout the process of my graduate school career at Ohio State. Both of them have been instrumental in my growth as a professional, and without their knowledge, support, input, and patience, this project would not have been possible.

I would also like to thank Dr. Jennifer Bogner, Michael Mahaffey, and other members or the Rehabilitation Psychology and TeamBI staff. Without Mike's organization in the data gathering process, this project could not have been completed. I also owe a debt of gratitude to Nancy Briggs for her statistical expertise.

Finally, I would like to express my appreciation to my family: To my husband, John, who has been my greatest supporter throughout my return to graduate school. Words cannot express how grateful I am to him for his willingness to travel with me through the ups and downs of this seven-year journey. To my son Keenan, who has endured many a stroller ride across campus, and has played quietly to allow Mommy to "get her homework done." To my father, who has been tireless in his support of my education and always ready to help with my "computer issues." And finally to my mother, whose example taught me about patience, perseverance, and keeping my priorities straight. 
VITA

January 24, 1967 ...................................... Born - Ann Arbor, Michigan

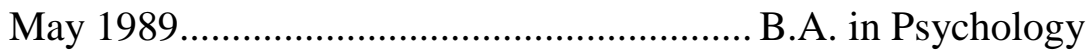

The University of Notre Dame du Lac

South Bend, Indiana

August 1990 ................................................ in Counseling Psychology

The University of Notre Dame du Lac

South Bend, Indiana

September 1990 - January 1992 ................... Psychology Assistant

Six County, Inc.

Coshocton and Zanesville, Ohio

January 1992 - September 1992 .................. Psychology Assistant

Interact Behavioral Healthcare, Inc.

Columbus, Ohio

December 1993 - May 1995........................ Psychology Assistant

St. Francis Hospital

Greenville, South Carolina

June 1995 - July 1998 ................................ Psychology Assistant/Psychology Intern

Department of Physical Medicine and

Rehabilitation, Dodd Hall

The Ohio State University

Columbus, Ohio

March 1998................................. in Counseling Psychology

The Ohio State University

Columbus, Ohio

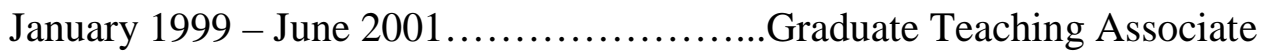

The Ohio State University

Columbus, Ohio 
September 2001 - August 2002.............Psychology Intern

The VA Pittsburgh Healthcare System

Pittsburgh, Pennsylvania

April 2003 - Present.....................Research Project Clinician

Department of Psychiatry

Brain Tissue Donation Program

The University of Pittsburgh Medical Center

Pittsburgh, Pennsylvania

\section{PUBLICATIONS}

$\underline{\text { Research Publication }}$

1. Arenth, P.A., Bogner, J.A., Corrigan, J. D., \& Schmidt, L. (2001). The utility of the Substance Abuse Subtle Screening Inventory - 3 for use with individuals with brain injury. Brain Injury, 15, (6), 499-510.

\section{FIELDS OF STUDY}

Major Field: Psychology

Studies in counseling psychology 
TABLE OF CONTENTS

Page

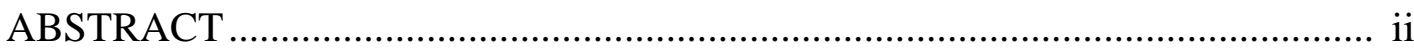

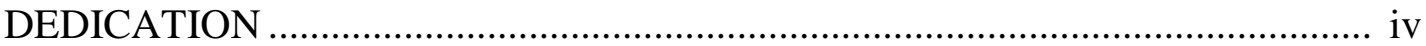

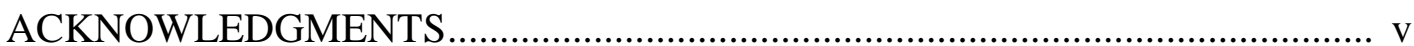

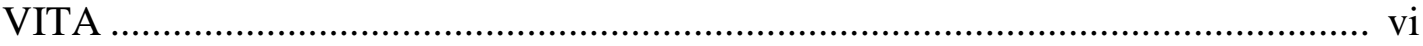

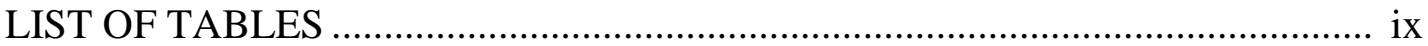

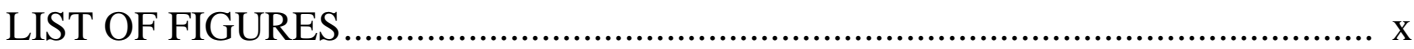

CHAPTER

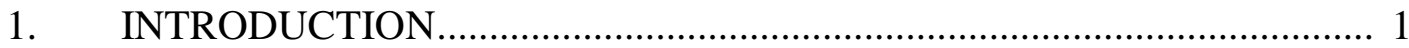

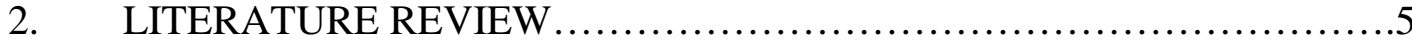

3. METHOD

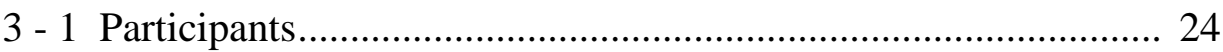

3 - 2 Instruments.......................................................................... 25

3 - 3 Procedures....................................................................... 30

3 - 4 Analyses of Data ........................................................................ 30

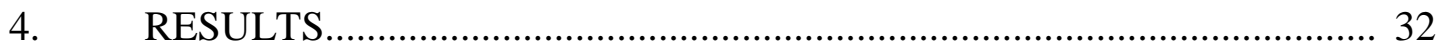

4 - 1 Demographic Description of Participants..................................... 32

4 - 2 Data Analysis ............................................................................ 36

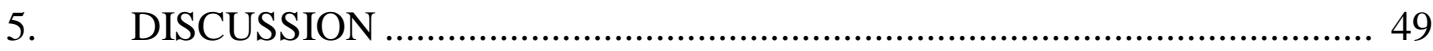

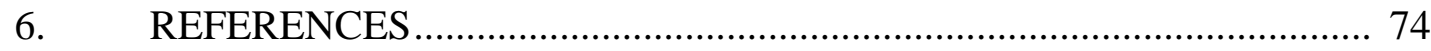




\section{LIST OF TABLES}

$\underline{\text { Table }}$

$\underline{\text { Page }}$

1. Descriptive demographic information for Group 1, Group 2 and Total Group presented in means and percentages.......................................... 33

2. Additional demographic variables with possible implications for cognitive functioning following TBI for Group 1, Group 2 and Total Group..................36

3. Group 1 and Group 2 means for SWLS, INCOM, PA, NA, PCS-12 and MCS-12 as well as follow-up ANOVAS for scales by group analysis....................... 37

4. Total Group Correlations for comparison with Vanderzee et.al. (1996) model..... 42

5. Split Group Correlations for comparsion with Vanderzee et al. (1996) model.......43

6. Between Group ANOVAS asking subjects to rate themselves compared to other TBI patients in terms of health, coping and in general. In addition, participants were asked to rate how they were doing compared to their physicians' predictions for their

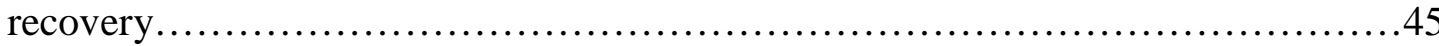

7. Means and standard deviations for subscales of the CHART $\ldots \ldots \ldots \ldots \ldots \ldots \ldots \ldots . . . . .46$

8. Participant responses to questions regarding contact with others with TBI and support group participation................................................... 48 


\section{LIST OF FIGURES}

$\underline{\text { Figure }}$

$\underline{\text { Page }}$

1. Line graph displaying Group 1 and Group 2 average response frequencies to four within-subjects questions regarding direction of comparison and emotion associated

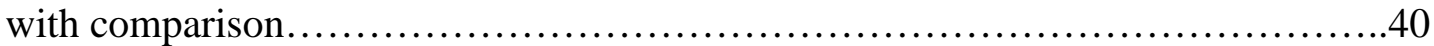

2. Bar graph displaying frequencies of Group 1 and Group 2 responses to question regarding downward comarison with associated positive affect..................60

3. Bar graph displaying frequencies of Group 1 and Group 2 responses to question regarding downward social comparison with associated negative affect............60

4. Bar graph displaying frequencies of Group 1 and Group 2 responses to question regarding upward social comparison with associated negative affect..............61

5. Bar graph displaying frequencies of Group 1 and Group 2 responses to question regarding upward social comparison with associated positive affect................61

6. Bar graph displaying percentages of Group 1 and Group 2 participants indicating that they currently have contact with another person with TBI, have attended a support group since release from rehabilitation, and if so, are still attending...............69

7. Bar graph displaying Group 1 and Group 2 frequencies of responses to question about the likelihood of attending a TBI support group............................. 70 


\section{CHAPTER 1}

\section{INTRODUCTION}

Social comparison theory is not new; even prior to Festinger's introduction of the term in his 1954 publication, the work of earlier researchers contained ideas about the tendencies of individuals to gauge their own status by comparing themselves to others, especially under stressful conditions (Sherif, 1936; Hyman, 1942; Stouffer, Suchman, DeVinney, Star \& Williams, 1949). In more recent years, however, social comparison theory has become recognized as an important and useful tool for examining mechanisms of coping and well-being among persons who have experienced serious illnesses and disabilities. (see, for example, a recent volume edited by B. P. Buunk \& F. X. Gibbons [1997], entitled Health, Coping and Well-Being: Perspectives from Social Comparison

\section{Theory).}

Social comparison theory, as originally described by Festinger (1954) began with the assumption that individuals are motivated to know if their opinions are correct and to know what they are capable of doing, or not doing. He asserted that human beings prefer to check themselves against objective standards. If, however, they can not test their opinions and abilities directly and objectively, Festinger (1954) suggested that individuals may attempt to evaluate how they are doing by comparing themselves with 
others. In 1959, Schacter suggested that feelings of uncertainty, especially in new situations where one may not be certain about the appropriate way to respond, might induce the need for comparison with others. As additional studies were done in this area, researchers began to suggest differentiating between upward comparison (comparison with others considered to be doing better as compared to oneself), and downward comparison (comparison with worse-off others). As the literature developed, seemingly contradictory information about upward and downward comparison began to emerge. It began to be apparent that the ways in which human beings compare themselves to others might be more complex than initially thought. Resulting research indicated that individuals could engage in social comparison for reasons other than for self-evaluation, and that directional comparisons could result in differing emotional responses (positive or negative). More recently, it has also been suggested that personality and emotional characteristics, as well as the distance from diagnosis or precipitating stressful event (i.e. adjustment level) can moderate social comparison activities and results.

In an interesting study comparing cancer patients to healthy individuals, VanderZee, Buunk, DeRuiter, Tempelaar,VanSonderen \& Sanderman (1996) presented a model examining how downward comparison may influence the relationship between physical distress and subjective well-being. The model suggested that physical distress (i.e., a serious illness) induces psychological distress, which in turn increases the desire for comparison with others. These authors asserted that individuals in this situation increase the frequency of downward comparison, which functions to affect subjective well-being positively. The data supported the general model, and found cancer patients did engage in downward comparison more often than healthy subjects did. In addition, 
results supported the hypotheses that although cancer patients suffer from increased levels of physical and psychological distress, they did not rate feelings of subjective wellbeing as lower than healthy subjects (perhaps because they tended to compare downward to less healthy others). Patients' perspectives regarding how they were doing were found to be a function both of the amount of psychological distress and the frequency of downward comparison. Overall, results seemed to indicate that social comparison was, indeed, the mediator controlling the ability of physical and psychological distress to threaten subjective well-being.

The purpose of the current study is to explore the use of social comparison by individuals who have sustained traumatic brain injuries. Traumatic brain injury (TBI) is one of the leading causes of death and permanent disability in the United States: Estimates suggest that 1.5 million traumatic brain injuries occur each year, and that approximately 50,000 of those injuries are fatal (Centers for Disease Control and Prevention, 2001). For those who survive TBI, an estimated 80,000 to 90,000 individuals sustain long-term or lifelong disability each year (Centers for Disease Control and Prevention, 2001). The direct and indirect costs of TBI are substantial: In 1995, such costs in the United States were estimated to be $\$ 56.3$ billion (Thurman [2000], as reported by the Centers for Disease Control and Prevention, 2001). The costs of TBI are affected by the demographics of those who typically sustain these types of injuries: A recent publication of the Traumatic Brain Injury Model Systems National Database (2002) indicated that, of the 3617 individuals in the database, $74 \%$ were male, and the mean age was 37 years. Max, MacKenzie and Rice (1991) commented on this by stating, 
"Because head injuries most often affect young people in their prime productive years, the resulting productivity losses are high compared to those resulting from other injuries or illnesses" (p. 76).

Head injuries are indeed costly; both in terms of financial resources, productivity, and emotional adjustment for patients and families whose lives are changed by the occurrence of the injury. Due to the prevalence and nature of TBI, it is important to work toward a better understanding of the processes involved in adjustment to disability for both the individuals who are injured and their family members. It is hoped that in doing so, more effective programs might be put in place to aid in the adjustment process, resulting in a reduction in the personal and societal costs mentioned above. It seems that if social comparison is found to be an important mediator in the ability of individuals to cope with the life altering changes produced by a brain injury, then those in charge of programs for recovery need to be certain to provide appropriate opportunities for comparison to occur. It is hoped that in exploring if, and how those who have sustained brain injuries make use of social comparison, we may gain a better understanding of the post injury coping processes, as well as some useful knowledge in this regard. 


\section{CHAPTER 2}

\section{LITERATURE REVIEW}

On the heels of Festinger's publication, Schacter(1959) conducted a study that yielded interesting results: He found that subjects involved in an experiment in which they were falsely told that they would be shocked, preferred to wait with another person who they believed was waiting for the same experience, as opposed to waiting alone, or with someone who they believed had already, or would not be shocked. In other words, Schacter suggested that individuals prefer to interact with someone whom they feel is "in the same boat" as they are.

As research continued, studies began looking not only at the reason that social comparison may occur, (i.e., feelings of uncertainty) but also at the emotional consequences of social comparison. In 1966, Hackmiller found evidence that individuals may tend to compare downward on dimensions about which they feel particularly threatened, and suggested that comparing to a worse-off other may allow them to feel better about themselves. That same year, Thornton and Arrowood (1966) suggested a potential conflict for an individual between finding out how well one is doing (evaluation) and feeling good about it (self-enhancement). They found that individuals tended to avoid downward comparison, when comparison involved negative traits (i.e., "neuroticism") as compared to positive traits ("social intelligence"). The authors 
suggested that it could be emotionally threatening to compare downward, as one might find similarities between oneself and another who is perceived to have a negative trait, or less of a positive trait. The authors suggested that selectively comparing in this way might allow individuals to avoid feeling like they belonged in the less desirable group.

Similarly, Brickman and Bulman (1977) suggested that individuals engaging in comparison may be doing so, not so much to gain valid information, but that they may compare in the direction from which they expect the most favorable outcome regarding their own feelings about themselves. They did suggest, however that despite the fact that upward comparison could be more emotionally painful, it could also be more valuable, in the sense that useful information could be gained through upward comparison which may allow the individual to improve his or her status.

In his 1981 study, Wills suggested that downward comparison could be useful, as an individual may experience an increased feeling of well-being by comparing to others who are not doing as well as themselves. He suggested that this could be most beneficial to emotional functioning in situations in which a person does not perceive that it is possible to take action that will improve the situation. In a study with seemingly contradictory findings, however, Wheeler and Miyake (1992) found that individuals indicated a preference for downward comparison when they felt good, and upward comparison when they felt bad.

In the first study applying these principles to individuals coping with real-life situations, Wood, Taylor and Lichtman (1985) worked with breast cancer patients and their spouses. They found a tendency among these patients to compare downward, no matter how seriously ill they were. In fact, $80 \%$ of the subjects stated that they felt that 
they were coping at least somewhat better than others in their situation. Wood et al. (1985) found that these patients and their husbands actually "made up" or imagined others worse off than themselves (i.e. women who's husbands left them because of their cancer), even if they had not met such others.

In additional medical studies on coping, Affleck and his colleagues (1987) found downward comparison to be prevalent among mothers of medically fragile infants. In general, these mothers reported that they felt that there were other families who were worse off than they were. Blalock, DeVellis, and DeVellis (1989) found those individuals with arthritis who perceived that they were better off as compared to others, were more satisfied with their functional abilities, independent of the perceived ability as such. Gibbons (1986) found that positive affect might result for individuals given comparison information about others who are worse off than they are. He found this to be especially true among individuals with low-self esteem, or depression, in whom a negative mood has been induced.

Lazarus and Folkman (1984) were the first to suggest differentiating between two different types of coping that they asserted might come into play when a person is confronted with a stressful situation. They termed the first type "problem focused", and suggested that this occurred in situations in which a person was most concerned with managing or solving the problem with which they are faced. On the other hand, Lazarus and Folkman (1984) suggested that an individual could also engage in a second form of coping, which they deemed "emotion focused". In this form, rather than trying to fix the problem, the individual would be most concerned with managing or alleviating the emotional issues raised by the stressful event that they are facing. That same year, Rolfe 
(1984) asserted that in the case of real-life stress, the main concern is to use affiliation with others to eliminate or reduce the stress rather than to compare one's emotional responses with those of others.

Taylor and Lobel's (1989) landmark study opened new possibilities to help evaluate the emerging contradictions in the literature. They called for further differentiation of social comparison in a fashion that was different, yet compatible, with the ideas of Lazarus and Folkman (1984). Taylor and Lobel (1989) suggested a differentiation be made between the purposes individuals have for engaging in comparisons. On one hand, they asserted, comparison can be engaged in for the purposes of affiliation with others or to gain information about how others respond and cope with stressful events. On the opposing hand, there are those comparisons that may be made by an individual for self-evaluative purposes. Taylor and Lobel (1989) asserted that these comparison activities diverge when an individual is faced with a threatening or stressful situation: They suggested that a person might tend to compare downward when the purpose of comparison is to evaluate how they are doing. The advantage of engaging in downward comparison in this situation is that it may ease the stress and feelings of threat by increasing the person's self esteem (i.e., "I am not doing as poorly as that other person"). Taylor and Lobel (1989) suggested that, on the other hand, when the purpose of comparison is to gain information, or affiliate with others, the tendency is to compare upward. They suggested that this would allow the person to gain information which may be helpful in allowing him/her to improve his/her situation, and simultaneously, the person may gain a sense of hope and motivation (i.e., learning more effective ways to cope and adapt). 
In his 1994 book chapter, Bram Buunk, asserted that the various, and seemingly contradictory interpretations could possibly be reconciled by examining the possibility of a "general drive upward". In his words:

It can be argued that self-enhancement and self-improvement can be met in a single process of affiliating with others doing better and contrasting oneself with others doing worse. Thus it can be expected that when individuals are asked how well they are doing, they will exhibit downward comparisons by saying "better than others", but when asked about whom they want to learn more, and with whom they want to affiliate, they will show a preference for upward comparisons by saying "about those doing better" ( $\mathrm{p}$. 216).

Despite the assertion by Schacter (1959) that situations in which individuals feel uncertain about their feelings, beliefs and responses tend to generate the need for comparison with others, Buunk (1994) reported that little actual research had been done to test this hypothesis in real-life stressful situations. Therefore, Buunk reported the results of three separate studies undertaken by himself and his colleagues (Buunk, VanYperen, Taylor \& Collins, 1991; Buunk \& Schaufeli, 1993; Buunk, 1995) which examined both emotional distress and uncertainty as related to a desire for affiliation. These three studies involved diverse groups: Individuals experiencing marital problems, assessment of burnout for nurses, and individuals with disabilities receiving monetary assistance from the government due to an inability to work. Buunk (1994) suggested that by looking at the consistent findings of these three studies, it might be possible to find explanations for the contradictions of previous research, and to refine the assertions of Taylor and Lobel (1989) further.

Results of the studies conducted by Buunk and his colleagues (Buunk, VanYperen, Taylor \& Collins, 1991; Buunk \& Schaufeli, 1993; Buunk, 1995) suggested that general measures of emotional distress (marital dissatisfaction, emotional exhaustion, and 
frustration) were indeed related to the desire to engage in social comparison for affiliation and informational reasons. In addition, in agreement with previous literature, results suggested that one of the main aspects of stress that causes an individual to engage in social comparison is the presence of feelings of uncertainty about one's own feelings and responses to a given situation. Finally, these studies suggested a need to distinguish between interest in information about others and interest in affiliation with similar others. The results across all three studies consistently found subjects to have a stronger interest in knowing about others, then in actually meeting or talking to those others.

In general, Buunk (1994) found results of his three experiments to be most consistent with the ideas presented in Taylor and Lobel's (1989) theory, as opposed to others (i.e. Wills, 1981). For example, results of the study with individuals experiencing marital problems indicated a greater preference for upward information. Buunk, VanYperen, Taylor \& Collins (1991) asserted that perhaps individuals in this situation wanted to find ways to improve their marriage, and therefore wanted to learn what couples with more successful marriages do, as opposed to individuals who have marriages which are less successful. It is also possible, that these couples did not want to associate themselves with the "worse-off" group, as this may have negative implications for the success of their own relationship.

The study of nurses (Buunk \& Schaufeli, 1993) revealed no evidence for downward comparison, suggesting that in a work situation, not even those under stress wanted to find out about those doing worse than they were (as others [i.e. Wills, 1981] would have asserted would make them feel better about themselves). Buunk (1994) noted that issues of compensation, competition, and career identity issues may be factors 
in this situation, where upward information may help one to get ahead, and one would not want to be associated with less competent others. In addition, the self-improvement hypothesis of Taylor and Lobel (1989) was supported by the fact that nurses in the "high control" category expressed an even more pronounced preference for upward comparison and that participants in the disability study preferred more upward comparison in the coping dimension. Buunk (1994) also suggested that the consistent findings of greater interest in information as compared to affiliation indicated a need to refine Taylor and Lobel's (1989) theory to consider the method of provision of information to those seeking comparison.

In looking at the direction of comparison in relation to Taylor and Lobel's (1989) theory, Buunk (1994) suggested some additional refinements: Recall that Taylor and Lobel (1989) asserted that individuals would tend to compare downward when evaluating themselves against others in order to increase their feeling of well-being, and would tend to compare upward for information and motivation for self-improvement. Buunk (1994) suggested that it is important to further narrow downward comparison based on the results of his study with individuals with disabilities. Findings of this study suggested that those with higher levels of stress had a greater prevalence of downward comparison, as compared to those with lower stress levels. In other words, the level of distress must be taken into account when predicting the tendency of a person to evaluate his or her situation by using downward comparison (Taylor and Lobel [1989] asserted that evaluative comparison was always in a downward direction). In addition, Buunk (1994) 
reported that he and his colleagues found the highest correlations between the use of downward comparison and expressions of threat to self-esteem, feelings of uncertainty, and negative affect.

Based on above assumptions along with some of the previously cited studies regarding social comparison (i.e., Festinger, 1954, Brickman and Bulman, 1977, Wills, 1981, Taylor, Wood, and Lichman , 1983), VanderZee, Buunk, DeRuiter, Tempelaar, VanSonderen, and Sanderman (1996) presented a model asserting that cancer patients experiencing physical and emotional distress may actively choose to compare downward to enhance their sense of well-being and therefore improve coping. In the words of VanderZee et al. (1996):

Our major assumption was that the more individuals are capable of finding and creating comparison to others and dimensions of that comparison make them feel better off, the better their subjective evaluations of well-being will be. Although cancer patients may suffer from longstanding physical distress, effective coping with this distress through social comparison may lead to a perceived subjective well-being that is comparable to the subjective well-being of healthy individuals (p. 454).

The results of the study generally supported the model, finding that although cancer patients experienced more physical and psychological distress, they did not report lower levels of subjective well-being as compared to the healthy subjects, and finding that social comparison activity appeared to be the mediating factor. The cancer patients for this study were contacted for participation in the study approximately 9 months after diagnosis. The authors asserted that the tendency for downward comparison observed in this study may occur more frequently soon after diagnosis, and may be less urgent after long term adaptation. They suggested that upward comparison for information and motivation may occur after the acute distress of diagnosis is past. 
In additional studies, Wood and VanderZee (1997) explain the Taylor and Lobel (1989) model in light of the Lazarus and Folkman (1984) model, by suggesting that Lazarus and Folkman's two primary coping mechanisms (problem solving and emotional regulation) come into play during periods of threat. They suggest that self-enhancement would override self-improvement during the initial diagnosis and recurrence. In addition, Taylor (1983) argues that after the initial stressor, negative emotions must be reduced and brought under control before problem solving can occur. In line with this idea, Wood et al. (1985) found that cancer patients made more downward comparisons closer to the time of initial diagnosis.

Wood and VanderZee (1997) suggested that it is also important to evaluate the dimensions that are being used for comparison, and the emotions that may be attached to those dimensions. For example, Wood and VanderZee(1997) point out that most of the evidence regarding cancer patient's preferences for upward comparison, looked at general physical condition as the dimension of interest. They suggest that for a cancer patient, who may be concerned about future declines in physical health, comparing downward may be threatening. In addition, the authors assert that cancer patients may find upward comparison threatening if they are asked to compare to targets which they have no hope of achieving, suggesting that it may be emotionally threatening to compare too far upward or downward. An additional study (Buunk, Collins, Taylor, Vanyperen \& Dakof, 1990) found a greater tendency among depressed individuals to respond with negative affect to both upward and downward comparison. The authors asserted that individuals experiencing depression might not be able to use comparison in either direction to aid in coping. More recently, Buunk and Brenninkmeijer (2001) found that 
depressed individuals with higher levels of social comparison orientation responded with relative negative affect when exposed to a description of a person who overcame their depression through active coping, as compared to when exposed to a description of an individual who's depression appeared to dissipate without effort on the part of the person described. Bogart and Helgeson (2000) also found that low self-esteem, low internal locus of control, and high illness uncertainty were associated with making more negative comparisons. Optimism has also been suggested as a possible moderator in social comparison activities (i.e. Lane, Gibbons, Gerard, Blanton \& Buunk, 2002). These findings taken together suggest that personality, mood, and comparison orientation may be some areas in need of further research in social comparison, but also may be important issues to consider when evaluating an individual for participation in groups or other therapeutic activities.

Of interest for our present purposes, are the results of Ybema and Buunk's (1995) study of individuals who were recipients of compensation due to disability. In this study, the subjects were evaluated along several stress dimensions: level of uncertainty, threat to self-esteem, degree of health problems, and levels of frustration regarding their situation. Results suggested that a higher degree of desire for social comparison for reasons of affiliation and information related to subjects levels of uncertainty and frustration, with the desire for information regarding others significantly higher than the desire for affiliation. The authors noted less or no relationship between the desires for social comparison related to self-esteem and health problems. In addition, when problem severity and coping success were evaluated as reasons for comparison, it was found that in general, there was a stronger tendency to compare upward for coping information, and 
less of a tendency to do so regarding problem severity. The authors assert that differences along these dimensions may be explained by considering that coping adequacy may be considered by subjects to be something that they may be able to improve, and therefore it may be helpful to compare upward to learn about more effective coping strategies. In comparison, problem severity may be considered to be something that one has less control over changing, and comparing to others doing better may only serve to decrease one's sense of well-being.

As can be seen, there has been an ongoing debate in the literature about when and why individuals make use of comparison. Recently, however two articles have attempted further explain that the seemingly contradictory findings may be due to differences in how comparison is being measured, and under what circumstances. For example, Gibbons, Lane, Gerrard, Reis-Bergan, Lautrup, Pexa and Blanton (2002) suggested that individuals may choose to compare differently when future performance and evaluation is likely or not likely, and depending on whether they have performed well or poorly on the task being evaluated. For example, if there will be future evaluations and an individual is motivated to enhance their performance (i.e., in a classroom setting), they may be more likely to engage in upward comparison for information from another successful person in order to improve. In situations where further evaluation is not a factor, downward comparison was found to be more likely, especially for those who did not do well, in order to make an individual feel better about a performance which they cannot change or enhance in the future. Overall, the findings of Gibbons et al. (2002) indicated that downward comparison occurs in situations in which an individual has experienced a difficulty which they will not be able to improve, and that the level at 
which a person chooses to compare (how high above/below self) can change with circumstances as well (i.e., lowering for a period after a failure). In an additional article, Wood, Michela, and Giordano (2000) also argued that the reasons for apparent contradictions in the literature may be due to the examination of different types of influences effecting social comparison activity: Specifically they suggest that models such as Wheeler and Miyake's (1992) propose that negative mood induces a tendency for individuals to think poorly of themselves and to compare both downwardly and upwardly with negative results. On the other hand, when an individual is feeling positive, he or she will tend to feel better about themselves whether they compare in either direction. Wood et al. (2000) argue that while this is true, it is also possible that an individual in a negative state may be motivated to find a way to feel better about themselves, and may actively choose to compare downward in order to achieve that result (as suggested by Wills' [1981] model). In other words, Wood et al. (2000) are suggesting that Wheeler and Miyake's (1992) study focuses on how mood influences comparison, and Wills' (1981) model focuses on the influence of motivation for self-enhancement. They argue that the results are not contradictory, but merely examining different relevant factors that may be involved in the social comparison process.

The purpose of the current study is to evaluate the social comparison behavior of a subset of persons who have experienced a traumatic brain injury (TBI). The initial hypothesis was that that effective comparison activity would change as the time from injury increased. In general, persons sustaining TBI seem to experience a "honeymoon" phase upon their release from the hospital. They tend to feel fortunate that they survived their injuries, and often express confidence in their ability to recover fully. This feeling 
may be related to a construct reported in the literature as "unrealistic optimism" (a review can be found in Klein \& Weinstein, 1997), which describes the tendency for individuals to feel that they are less vulnerable than most others or average others to negative events. In addition, those who have survived brain injury may have the support of friends and family who have rallied around them during the acute phases of their recovery in intensive care and inpatient rehabilitation. It was hypothesized that during this phase, downward comparison may serve to allow the person to feel that they have been "lucky" in comparison to others who have sustained similar injuries. Upward comparison with "old self" or "old colleagues" would not serve to promote adaptive feelings of well-being, and would therefore not be utilized as readily by individuals during these earlier stages of recovery.

As time from injury increases however, it seems that individuals who have survived brain injury are forced to acknowledge the fact that some of the effects of injury may be lasting, or even permanent. If people are not able to return to their previous levels of social, physical or occupational functioning after a few months, they may begin to question their ability to do so. In addition, the initial strong social support of friends and family may begin to wane. As a result, the author expected that appropriate comparison activity during this time may be important for positive adjustment to disability, but may be conducted in a different manner: In general, it was hypothesized that positive adjustment for an individual would be associated with upward comparison for informational purposes and downward comparison to evaluate how they were doing, as suggested by Taylor and Lobel (1989). Effective upward comparison would likely involve a shift from comparison to "old self" and "old colleagues" to comparison to 
others who are functioning well with injuries similar to those sustained by the individual. By engaging in social comparison in these ways, individuals would maximize positive affect by gaining continued hope and inspiration regarding their recovery, while at the same time, gaining a sense that they are doing well in comparison to others. Engaging in less effective comparison activities could be associated with less than optimal adjustment, and possible depression.

The literature also suggests that the presence of significant levels of depression may also moderate comparison activity (i.e. Buunk, Collins, Taylor, VanYperen \& Dakof, 1990). Specifically, it was hypothesized that depression would cause an individual who is in the process of adjusting to a disability to experience negative affect in general from both upward and downward comparison. In addition, however, it would be expected that a subject experiencing depression would not be able to use either comparison upward or downward to effectively aid in coping: Downward comparison would not be utilized to achieve an increased sense of subjective well-being, nor would upward comparison be used later for information, motivation or affiliation. In essence, moderate to severe depression would disrupt the "general drive upward" asserted by Buunk (1994).

It also seemed important to clarify the dimensions along which participants in the current study would be asked to compare. The literature seems to suggest that comparison activity may also differ depending on whether a subject is comparing an aspect of his situation, which he considers to be under his control or within his target range for achievement. (i.e., problem severity versus coping skills). Attempts were made to explore this in the present study. 
In addition to examining the different ways that social comparison may be used at different times during recovery from TBI, the findings of the current study were evaluated to see how well they fit with the previously mentioned model of VanderZee and her colleagues (1996). As described earlier, these authors worked with a sample of cancer patients to evaluate the influence of downward comparison on the relationship between physical distress and subjective well-being. The results of VanderZee et al. (1996) supported their hypotheses that physical distress gives rise to psychological distress, which in turn increases an individual's desire for comparison. They further asserted that downward comparison in this situation provides individuals with a sense that they are doing relatively well in comparison to others, and this results in increased feelings of subjective well-being. Upward comparison activities were not included in the VanderZee et al. (1996) model, but were also explored in the current analysis.

In summary, the first several months following a traumatic brain injury appear to be a time of significant physical and emotional adjustment. The current study therefore examined social comparison activity for groups of subjects at two different times during the acute adjustment period: Within 30 days of discharge from rehabilitation $(0-30$ days $=$ Group 1), and at approximately 6 months post rehabilitation (180-210 days = Group 2). Specific hypotheses were:

1. Due to the physical and emotional adjustment associated with recovery in the first year post-injury, the first hypothesis was that subjects across both groups would express significant physical and emotional distress. The author expected to find no significant differences in overall levels of distress, however the following differences were hypothesized: 
a. Expression of physical distress was expected decrease somewhat with continued physical recovery; therefore scores on a measure of physical health were expected to be significantly higher for Group 2 as compared to Group 1.

b. Emotional distress was expected to increase as subjects recognize and adjust to the fact that some of their disability is likely to be lasting or permanent, therefore scores on a measure of mental health were expected to be significantly lower for Group 2 as compared to Group 1.

2. Previous studies (i.e. VanderZee et al., 1996) have asserted that appropriate use of social comparison activity allows for the maintenance of subjective well-being, despite physical distress caused by illness. Based on these findings, no significant differences were expected in measures of subjective well-being (including satisfaction with life and positive and negative affectivity) between Group 1 as compared to Group 2. In addition, it was hypothesized that subjective well-being would be maintained for both Groups at levels comparable to healthy individuals.

3. It was hypothesized that the need for social comparison would be maintained at similar levels across both groups, but the direction, relative evaluation, and purpose for using comparison would differ between groups in the following manner:

a. Group 1 would be significantly more likely to report the use downward comparison for the purpose of evaluating physical functioning, with associated positive affect, as compared to Group 2.

b. As compared to Group 1, Group 2 would be significantly more likely to report the use of upward comparison for the purpose of gaining information, with associated positive affect, as they begin to realize that there may be some lasting effects from 
their injuries and become interested in seeking information about how others cope. It was expected that they would continue to report the use of downward comparison for evaluation of physical functioning with associated positive affect.

4. It was hypothesized that correlations found between variables would generally match those found by VanderZee et al. (1996) with one exception: VanderZee and her colleagues found a positive correlation between physical and psychological distress. It was hypothesized that for the current sample, a negative correlation will be found between these variables because, even as physical health was generally expected to improve with time out from injury, mental distress was expected increase with the realization that disability may be lasting or permanent. Other correlations which were expected to match the model of VanderZee et al. (1996) were as follows:

a. It was hypothesized that scores measuring mental health would be negatively correlated with scores measuring the need for social comparison (corresponding with VanderZee et al.'s finding of a positive correlation between psychological distress and need for comparison).

b. For VanderZee et al. (1996), the need for social comparison was positively correlated with the frequency of downward comparison, which was further positively correlated with positive affective response. In expanding from VanderZee at al (1996) to include upward as well as downward comparison:

1. For Group 1: It was expected that the need for social comparison would be positively correlated with the frequency of downward comparison with associated positive affect. 
2. For Group 2: It was expected that the need for comparison would be positively correlated with the frequency of upward comparison with associated positive affect. Group 2 was also expected to display a positive correlation between the need for comparison downward and associated positive affect.

e. From the VanderZee (1996) model, relative evaluation (downward comparison resulting in positive affect) was positively correlated with subjective well-being. Expanding from the VanderZee (1996) model, it was expected in the current study that appropriate social comparison activities at different stages of recovery would be associated with positive measures of satisfaction with life. Specifically:

1. In the first group, downward comparison with associated positive affect for the purposes of evaluating physical functioning would be positively correlated with satisfaction with life and positive affectivity, and would be negatively correlated with negative affectivity.

2. In the second group, upward comparison with associated positive affect for the purposes of gaining information would be positively correlated with satisfaction with life and positive affect, and would be negatively correlated with negative affectivity. Downward comparison with positive affect for the purpose of evaluating physical functioning would continue to be positively correlated with satisfaction with life and positive affectivity, and negatively correlated with negative affectivity.

f. Psychological distress and physical distress would be negatively correlated with subjective well-being. 
g. Psychological distress would be negatively correlated with subject's ratings of their health, coping, and general functioning as compared to others who have sustained brain injuries.

h. Negative affectivity would be negatively correlated with subjects ratings of their need for social comparison activity

5. In this study, the author also explored whether subjects compare not only to others with similar injuries, but also to their perceptions of their physician's prognosis for them early in recovery. It is expected that these comparisons will be reported.

6. Finally it was hypothesized that on objective measures of disability, subjects in both groups would obtain significantly lower scores as compared to non-disabled individuals in terms of physical and cognitive independence, mobility, occupation, social integration, and economic self-sufficiency. It was expected that despite insignificant differences between groups, individuals in Group 2 would report improvement in functioning across these domains as compared to Group 1. 


\section{CHAPTER 3}

\section{METHOD}

\section{$\underline{\text { Participants }}$}

The sample for this study consisted of research participants recruited from the follow-up clinic of a Traumatic Brain Injury Unit of an inpatient rehabilitation facility at a large Midwestern University medical center. They were participating in rehabilitation therapies on an outpatient basis and were returning for follow-up medical appointments in the clinic setting. They were receiving case management via a structured program. All had a diagnosis of traumatic brain injury (TBI). Upon obtaining consent, some basic medical and demographic information was gathered from subjects' emergency room, acute hospitalization, and rehabilitation hospitalization medical records, and placed in a common database.

The participant pool consisted of a subset of all persons with brain injury. Those included in this sample had experienced significant loss of consciousness and coma, experienced periods of post-traumatic amnesia, and had required inpatient rehabilitation. The study sample was biased by the exclusion of those sustaining brain injuries who died as a result of their injuries, those currently in coma or persistent vegetative state, those with mild injuries or non-traumatic injuries, those who did not receive inpatient rehabilitation, and those who could not be reached for follow-up interview. 


\section{$\underline{\text { Instruments }}$}

Physical and Mental Health: The SF-12 Physical and Mental Health Summary Scales (Second Edition) was used to assess levels of physical and emotional health among subjects. The SF-12 is a shortened version of the SF-36, which has been widely used in larger studies. The SF-12 was developed specifically to provide a valid shorter alternative to the longer SF-36. The SF-12 questionnaire asks respondents questions about both physical and emotional issues: physical functioning, role limitations due to physical health problems, bodily pain, general health, vitality (energy/fatigue), social functioning, role limitations due to emotional problems, and mental health (psychological stress and psychological well being). (pg. 11). The twelve standard questions of the SF12 consist of eight likert-type questions, and four yes/no responses. The SF-12 is scored using a norm based method: a computer program transforms PCS-12 and MCS-12 scale scores using regression weights and constants so that results can be directly compared to the general U.S. population norms with a mean of 50 and a standard deviation of 10 . The SF-12 Scoring Manual (Ware, Kosinski and Keller, 1995) reports the U.S. population means for age $35-44$ to be $52.18(\mathrm{SD}=7.30)$ for the PCS-12 and to be 50.10 $(\mathrm{SD}=8.62)$ for the MCS-12. In the current study, the SF-12 was used to provided information about both emotional and physical issues that may play roles in adjustment to disability.

\section{Social Comparison: The Iowa-Netherlands Comparison Orientation Measure} (INCOM) was developed as a measure of individual differences in the need to engage in social comparison activity. It was administered to several thousand people in 2 cultures, and was found to predict comparison behavior effectively (Gibbons \& Buunk, 1999). 
The scale consists of 11 questions about social comparison activity. Participants are asked to answer questions using a 5 point Likert type scale with responses ranging from 1) disagree strongly to 5) agree strongly. Two items of the scale are reverse scored. Scores can therefore range from a low of 11 to a highest possible score of 55 with a higher score indicating an increased need to engage in social comparison activity. The mean score for a sample of adult males in the United States was found to be 35.33 with a standard deviation of 6.35 (Gibbons \& Buunk, 1999). This measure was used to assess general social comparison traits for given subjects in the current study.

In addition to INCOM, some specific questions regarding were used to evaluate direction of comparison (downward or upward), types of comparison, and relative evaluation. The following questions are taken from Buunk, Collins, Taylor Vanyperen and Dakof (1990), and were adapted for use with individuals with TBI. Downward comparison was assessed first by stating:

Some people have told us that when they see TBI patients who are not doing as well as they are, it makes them feel lucky and grateful that they are not in worse shape themselves. Other people have told us that when they see TBI patients who are not doing as well as they are, it makes them feel worse. For these people, seeing TBI patients who are worse off, only increases their fears and anxieties. (p. 1240)

Subjects were then be asked "how often have you felt lucky or grateful when exposed to worse off others?" and were asked to respond on a 4-point scale ranging where $1=$ never, $2=$ rarely, $3=$ sometimes and $4=$ often. Subjects giving a rating higher than one were then be asked to give an example of a time when they have felt a need for such comparison. They were then asked, "How often have you felt fearful or anxious in response to worse off others?," using the same scale and followed by a request for an example for those with ratings greater than one. 
The same procedure was then used to evaluate upward comparison. Subjects were then told:

Some people have told us that when they see TBI patients who are doing better then they are, it makes them feel frustrated or depressed. Other people have told us that they feel inspired or comforted when they see other TBI patients who seem to be doing better than they are. (p. 1241)

Again, questions regarding frequency along the same 4-point scale were utilized, with examples requested for responses greater than 1. Each question, therefore had a maximum score of four. The examples were evaluated to explore the dimensions along which comparisons are being made.

Following this, the subjects were asked three questions to evaluate how they would rate themselves relative to other TBI patients (adapted from VanderZee, Buunk and Sanderman, 1996). These questions were simply, "How do you feel that you are doing in respect to your health/coping/general situation, as compared to other TBI patients?" Participants are asked to answer questions using a 5 point Likert type scale with responses ranging from 1) much worse to 5) much better, for each question. Subjects were also surveyed about whether or not they have attended a TBI support group (yes/no and if yes, are you still attending?), and their likelihood of attending such a group should one be available to them (using a five point scale ranging from 0 ) no likelihood to 4) strong likelihood).

Subjective Well Being: "Satisfaction with life", "positive affectivity" and "negative affectivity" have long been suggested to be separate constructs involved in 
assessment of subjective well-being (i.e. Andrews \& Withey [1976] as cited in Diener, Emmons, Larsen \& Griffin, 1985). As a result, the following scales were used in the present study:

Satisfaction with Life was measured using the Satisfaction With Life Scale (SWLS). This instrument consists of five items containing statements about global life satisfaction. Participants were asked to answer questions using a 7 point likert type scale, with responses ranging from 1)totally agree to 7)totally disagree. Scores on this instrument can range from a low of 5 for a high score of 35, with a higher score indicating higher life satisfaction. Participants in the original research for construction of the SWLS by Deiner and his colleagues (1985) were American undergraduate students $(\mathrm{M}=23.5, \mathrm{SD}=6.43)$ and geriatric participants $(\mathrm{M}=25.8$, no $\mathrm{SD}$ given). This scale has been studied widely with other samples since that time. Of particular interest for the current study, Corrigan, Bogner, Mysiw, Fugate, and Clinchot (1999) reported SWLS mean scores at 1 year post $\mathrm{TBI}(\mathrm{M}=19.58, \mathrm{SD}=8.29)$ and 2 years post injury $(\mathrm{M}=$ 20.98, $\mathrm{SD}=9.39$ ).

Positive and Negative Affectivity: Positive mood states (i.e. enthusiasm, feeling active and alert) and negative mood states (i.e. feelings of distress, anger, nervousness etc.) have consistently emerged as dominant and independent dimensions in studies of the structure of affect. (Watson, Clark and Tellegen, 1988). The Positive and Negative Affect Schedule (PANAS) was used to measure the constructs of positive and negative affectivity in the current study. This is a brief, ten-item mood scale in a checklist format, which can be administered using multiple time frames. (i.e., how the subject feels today, past few weeks, past year, etc.). For the current study, participants were asked to rate 
how they had been feeling in the past four weeks in responses to words describing positive emotions (i.e. interested) and negative emotions (i.e. distressed). The PANAS scale is comprised of 20 such words, ten of which represent positive emotions, and ten of which represent negative emotions. Responses are given on a five point Likert type of scale ranging from 1) very slightly or not at all to 5) extremely. Scores are then summed for positive words to obtain the PA (Positive Affect) subscale score and for negative words to obtain the NA (Negative Affect) subscale score. Each subscale therefore has a possible score ranging from a low of 10 to a high score of 50. Watson, Clark and Tellegen (1988) developed the PANAS using a large sample of undergraduate psychology students. The mean score for that group when asked to rate affect "during the past few weeks", was $32.0(\mathrm{SD}=7.0)$ for the PA subscale and $19.5(\mathrm{SD}=7.0)$ for the NA subscale.

Disability: The shortened version of the Craig Handicap Assessment and Reporting Technique (CHART- Short Form) was used as an objective measure of functioning (Whiteneck, Charlifue, Gerhart, Overhosler \& Richardson, 1992). This instrument consists of 20 multiple choice and single word response questions. Each of the six subscales of the chart have a maximum score of 100 , which is considered to be the level of functioning typical of an average, non-disabled person. The six subscales measure physical independence, cognitive independence, mobility, occupational functioning, social integration, and economic self-sufficiency. A score lower than 100 on a particular subscale indicates some degree of impairment in that area as compared to a typical non-disabled individual (Whiteneck et al., 1992) 


\section{$\underline{\text { Procedures }}$}

Subjects were recruited for participation at discharge from acute rehabilitation. They were randomly assigned to one of two groups, based on the time of assessment: Those within 30 days of discharge from acute care (Group 1); and 180-210 days post discharge (Group 2). Participants were assessed via a phone interview during the time period designated by group assignment. The interview involved some questions regarding personal history and demographic information. In addition, subjects were asked to respond to the group of short questionnaires to assess physical and mental distress, social comparison, subjective well-being, and ratings of disability as mentioned above. Statistical comparisons between groups will then be conducted.

\section{Analysis of Data}

To assess the initial hypotheses of the current study, the means and standard deviations of measures of physical health (PCS-12) and mental health (MCS-12) for Group 1 and Group 2 were compared with the means and standard deviations for the U.S. population means for these measures. Then, to address the main research questions regarding between-group differences, a multivariate analysis of variance (MANOVA) was conducted with group as the independent variable, and physical and mental health, need for social comparison, subjective well-being (including satisfaction with life and positive and negative affectivity) as dependent variables. An additional MANOVA was conducted to assess for group differences in the use of upward versus downward social comparison and associated positive versus negative emotional association with comparison activity. For this second MANOVA, group was again used as the independent variable. Direction of social comparison activity (upward or downward) and 
emotion associated with comparison (positive versus negative affect) were used as dependent variables. The use of the MANOVAs allowed for the simultaneous assessment of the effects of group membership on all of the dependent variables, controlling the experimentwise error rate and increasing power, as opposed to conducting individual ANOVAs. Univariate ANOVAs were conducted to evaluate for possible between group differences in ratings of health, coping, and general functioning compared to other individuals who have sustained brain injuries, and also to explore whether Groups differed on their ratings of their health compared to their perceptions of how their physicians told them they would do early in recovery.

VanderZee and her colleagues (1996) tested their model by computing the correlations between model variables, and then by bringing all of the variables into a linear structure model with one exogenous variable (physical distress) and five endogenous variables (psychological distress, need for comparison, downward comparison, relative evaluation, and subjective well-being). They then estimated the model parameters using LISREL. Due to the limited sample size in the current study, we were not able to conduct the path analysis identical to the one conducted by VanderZee and her colleagues (1996). In the current study, however, correlations were computed for pairs of variables, and relationships examined to determine if correlational patterns were similar to those found by VanderZee et al. (1996). In other analyses, as the data associated with the CHART ratings were found to be skewed, a Mann-Whitney Test was conducted to evaluate for differences between groups. Finally, differences in frequencies of responses to questions regarding support group interest and participation were explored for Group 1 as compared to Group 2. 


\section{CHAPTER 4}

\section{RESULTS}

The purpose of this chapter is to provide a demographic description of the participants in this study, and to present the results of statistical analyses performed.

\section{Demographic Description of Participants}

Table 1 provides demographic characteristics of the 58 participants in the study. Information is separated by time of interview and also provided for the group as a whole. Participants in Group 1 were surveyed within the first month of discharge from the rehabilitation hospital (1-30 days post rehabilitation). Group 2 was surveyed within the sixth month after release from the rehabilitation hospital (180-210 days postrehabilitation). Each group contained an equal percentage of male and female participants (72.4\% male and $27.6 \%$ female). Groups were fairly comparable in terms of marital status, employment levels, education, and cause of injury. The mean age of the Total Group was 37.4 years, with a standard deviation of 15.3 and a range of 16-68 years. The percentage of males $(72.4 \%)$ to females $(27.6 \%)$ is approximately the same as has been found in other research in the population of TBI survivors receiving acute 


\begin{tabular}{|c|c|c|c|}
\hline Demographic Category & Group 1 & Group 2 & Total Group \\
\hline & $(\mathrm{n}=29)$ & $(\mathrm{n}=29)$ & $(\mathrm{n}=58)$ \\
\hline \multicolumn{4}{|l|}{ Age } \\
\hline$\overline{\text { Mean }}$ & 37.6 years $(\mathrm{SD}=17.1)$ & 37.2 years $(\mathrm{SD}=13.7)$ & 37.4 years $(\mathrm{SD}=15.34)$ \\
\hline \multicolumn{4}{|l|}{ Gender } \\
\hline$\overline{\text { Male }}$ & $72.4 \%$ & $72.4 \%$ & $72.4 \%$ \\
\hline Female & $27.6 \%$ & $27.6 \%$ & $27.6 \%$ \\
\hline \multicolumn{4}{|l|}{ Race } \\
\hline Caucasian & $82.8 \%$ & $89.7 \%$ & $86.2 \%$ \\
\hline Black & $13.8 \%$ & $6.9 \%$ & $10.3 \%$ \\
\hline Other Races & $3.4 \%$ & $3.4 \%$ & $3.4 \%$ \\
\hline \multicolumn{4}{|l|}{ Marital Status } \\
\hline Single & $48.3 \%$ & $48.3 \%$ & $48.3 \%$ \\
\hline Married & $31.0 \%$ & $34.5 \%$ & $32.8 \%$ \\
\hline Divorced & $13.8 \%$ & $17.2 \%$ & $15.5 \%$ \\
\hline Separated & $3.4 \%$ & $0.0 \%$ & $1.7 \%$ \\
\hline Cohabitating 7 years & $3.4 \%$ & $0.0 \%$ & $1.7 \%$ \\
\hline \multicolumn{4}{|l|}{ Employment Status } \\
\hline Competitively Employed & $65.5 \%$ & $69.0 \%$ & $67.2 \%$ \\
\hline Unemployed & $10.3 \%$ & $17.2 \%$ & $13.8 \%$ \\
\hline Retired Due to Disability $(<60)$ & $10.3 \%$ & $0.0 \%$ & $5.2 \%$ \\
\hline Student (full time) & $10.3 \%$ & $3.4 \%$ & $6.9 \%$ \\
\hline Retired Due to Age $(>60)$ & $0.0 \%$ & $6.9 \%$ & $3.4 \%$ \\
\hline Homemaker & $3.4 \%$ & $3.4 \%$ & $3.4 \%$ \\
\hline \multicolumn{4}{|l|}{ Education Level } \\
\hline Less than High School & $27.6 \%$ & $31.0 \%$ & $29.3 \%$ \\
\hline GED & $3.4 \%$ & $0.0 \%$ & $1.7 \%$ \\
\hline High School & $41.4 \%$ & $37.9 \%$ & $39.7 \%$ \\
\hline Working Towards Associates Degree & $6.9 \%$ & $3.4 \%$ & $5.2 \%$ \\
\hline Associates Degree & $6.9 \%$ & $10.3 \%$ & $8.6 \%$ \\
\hline Working Towards Bachelors Degree & $10.3 \%$ & $13.8 \%$ & $12.1 \%$ \\
\hline Bachelors Degree & $3.4 \%$ & $0.0 \%$ & $1.7 \%$ \\
\hline Doctorate & $0.0 \%$ & $3.4 \%$ & $1.7 \%$ \\
\hline \multicolumn{4}{|l|}{ Glascow Coma Scale } \\
\hline $13-15$ (Mild) & $34.4 \%$ & $27.6 \%$ & $31.0 \%$ \\
\hline 9- 12 (Moderate) & $0.0 \%$ & $10.3 \%$ & $5.2 \%$ \\
\hline $0-8$ (Severe) & $20.6 \%$ & $17.2 \%$ & $19.0 \%$ \\
\hline Unknown & $44.8 \%$ & $44.8 \%$ & $44.8 \%$ \\
\hline \multicolumn{4}{|l|}{ Hospitalization Length of Stay (LOS) } \\
\hline Acute Hospital Mean LOS & 12.0 days $(\mathrm{SD}=8.0)$ & 14.1 days $(\mathrm{SD}=10.6)$ & 13.0 days $(\mathrm{SD}=9.4)$ \\
\hline Inpatient Rehabilitation Mean & 17.2 days $(\mathrm{SD}=9.2)$ & 20.0 days $(\mathrm{SD}=12.3)$ & 18.6 days $(\mathrm{SD}=10.9)$ \\
\hline \multicolumn{4}{|l|}{ Cause of Injury } \\
\hline Vehicular Crashes & $69.0 \%$ & $75.8 \%$ & $72.4 \%$ \\
\hline Falls & $17.2 \%$ & $20.7 \%$ & $19.0 \%$ \\
\hline Assault & $6.9 \%$ & $3.4 \%$ & $5.2 \%$ \\
\hline Pedestrian vs. Car & $3.4 \%$ & $0.0 \%$ & $1.7 \%$ \\
\hline Gun Shot Wound & $3.4 \%$ & $0.0 \%$ & $1.7 \%$ \\
\hline
\end{tabular}

Table 1: Descriptive demographic information for Group 1, Group 2 and Total Group presented in means and percentages. 
rehabilitation (i.e., Burnett, Kolakowsky-Hayner, Slater, Stringer, Bushnick, Zafonte, \& Cifu, 2003). As has been found in previous research, the majority of participants in the present study were single males, with high-school or less education, and less than $75 \%$ of the individuals were employed full- or part-time at the time of injury (i.e., Burnett et al., 2003).

Table 1 also contains information regarding Glasgow Coma Scale (GCS) ratings for both the Total Group and for each group individually. Initial Glagcow Coma Scale scores are often used as measures of severity of injury. This information is generally collected early in acute care, and was available for only 32 of the subjects (26 scores were not available due to intubation or chemical paralysis at the time this measure would normally be taken). Of the 32 available scores for the Total Group, 56.3\% were in the 13-15 range, often considered to indicate mild brain injury, $9.4 \%$ were in the $9-12$ range, often considered to indicate moderate injury, and 34.4\% were in the 3-8 range, generally considered to indicate severe brain injury (Rimel, Giordani, Barth, \& Jane, 1982). The mean GCS score for the Total Group was 11.09, with a standard deviation of 4.45, which is slightly higher than found in other samples (i.e., Burnett et al., 2003). It should be noted, however that intubation or chemical paralysis generally indicates more severe brain injury. For this reason, if the data from the 26 subjects with missing GCS scores could have been included, most scores would likely have fallen in the severe range, significantly lowering the mean GCS score for the group.

Table 1 also shows acute hospital and inpatient rehabilitation days, which were slightly low for the Total Group compared to the average 21 day acute length of stays and 
the average 30 day rehabilitation length of stays reported in previous samples (TBI Model Systems National Database, 2002). Finally a cause of injury is reported in Table 1: Cumulatively, $72.4 \%$ of injuries were due to vehicular crashes (combining auto, motorcycle, and snowmobile percentages), $19.0 \%$ were due to falls, $5.2 \%$ were due to assault, and the remaining $3.4 \%$ of injuries in this sample resulted from pedestrians being struck by cars, and gun shot wounds (1.7\% each). Previous samples also indicated that the majority of injuries are motor vehicle related (53.6\%), but reported higher levels of violence and fall related injuries, other injuries. (i.e., Burnett et al., 2003).

Due to possible contributions to cognitive status, additional participant information considered included whether or not the individuals had a history of psychiatric treatment, previous TBI, learning difficulties, or special education. Information obtained for these demographic categories is displayed as frequencies and percentages in Table 2. The two groups were fairly well matched in terms of histories of traumatic brain injury, psychiatric care, need for special education, and learning problems.

The sample appeared to be consistent with previous prospective samples from this medical center, but may show some differences from the national population of patients with TBI receiving rehabilitation. Specifically, as compared with the most recent reports from the Model Systems Database (TBI Model Systems National Database, 2002) the present sample contains reduced representation of minority groups. Education levels and employment status appear to be somewhat higher, and length of acute and rehabilitation hospitalization is reduced for the present group as compared to previous samples. 


\begin{tabular}{cccc}
\hline Demographic Category & Group 1 & Group 2 & Total Group \\
\hline Hx Previous TBI & Frequency $(\mathrm{n}=29)$ & Frequency $(\mathrm{n}=29)$ & Frequency $(\mathrm{n}=58)$ \\
Yes & $10.3 \%$ & $3.4 \%$ & $6.9 \%$ \\
No & $89.7 \%$ & $96.6 \%$ & $93.1 \%$ \\
& & & \\
Hx Psychiatric Tx & & & $8.6 \%$ \\
Yes & $6.9 \%$ & $10.3 \%$ & $91.4 \%$ \\
No & $93.1 \%$ & $89.7 \%$ & \\
& & & $13.8 \%$ \\
Hx Special Education & & & $86.2 \%$ \\
Yes & $13.8 \%$ & $13.8 \%$ & \\
No & $86.2 \%$ & $86.2 \%$ & \\
& & & $24.1 \%$ \\
Hx Learning Problems & & & \\
Yes & $20.7 \%$ & $27.6 \%$ & \\
No & $79.3 \%$ & $72.4 \%$ & \\
\hline
\end{tabular}

Table 2: Additional Demographic variables with possible implications for cognitive functioning following traumatic brain injury for Group 1, Group 2 and Total Group.

\section{Data Analysis}

The first hypothesis predicted that participants across both groups would express both physical and emotional distress, with no significant differences found in overall levels of distress. As noted in Table 3, the mean PCS-12 score for both Group $1(\mathrm{M}=39.23$, $\mathrm{SD}=11.33)$ and Group $2(\mathrm{M}=42.82, \mathrm{SD}=14.30)$ fell in a range 1 standard deviation below the mean score for the U.S. population aged 35-44 $(\mathrm{M}=52.18, \mathrm{SD}=7.30)$. The mean MCS-12 score for Group 1 (51.90, SD=8.70) was slightly above the U.S. population 
mean for 35-44 year olds $(\mathrm{M}=50.10, \mathrm{SD}=8.62)$, while the mean score for Group 2 $(\mathrm{M}=46.96, \mathrm{SD}=7.41)$ was slightly lower than the same U.S. population mean. Both Group 1 and Group 2 scores were within one standard deviation of the U.S. population mean for 35-44 year olds for this measure. Therefore, this hypotheses was not completely supported; only physical health was rated as greater than one standard deviation below the population norm for this measure (suggesting physical distress), with mental health ratings clustering within the normative range.

\begin{tabular}{|c|c|c|c|}
\hline SCALE & GROUP MEANS & $\mathrm{F}$ & $\mathrm{p}$-value \\
\hline & $($ all $n=29)$ & $(\mathrm{df}$ for all $=1,56)$ & \\
\hline SWLS & $\begin{array}{l}\text { Group } 1=21.83(\mathrm{SD}=7.12) \\
\text { Group } 2=21.52(\mathrm{SD}=8.22)\end{array}$ & .024 & .878 \\
\hline INCOM & $\begin{array}{l}\text { Group } 1=31.72(\mathrm{SD}=9.18) \\
\text { Group } 2=36.66(\mathrm{SD}=8.58)\end{array}$ & 4.467 & .039 \\
\hline PA & $\begin{array}{l}\text { Group } 1=34.28(\mathrm{SD}=8.35) \\
\text { Group } 2=31.10(\mathrm{SD}=9.41)\end{array}$ & 1.845 & . 180 \\
\hline NA & $\begin{array}{l}\text { Group } 1=17.17(\mathrm{SD}=8.56) \\
\text { Group } 2=20.79(\mathrm{SD}=8.48)\end{array}$ & 2.617 & 111 \\
\hline PCS-12 & $\begin{array}{l}\text { Group } 1=39.23(\mathrm{SD}=11.33) \\
\text { Group } 2=42.82(\mathrm{SD}=14.30)\end{array}$ & 1.128 & 293 \\
\hline MCS-12 & $\begin{array}{l}\text { Group } 1=51.90(\mathrm{SD}=8.70) \\
\text { Group } 2=46.96(\mathrm{SD}=7.41)\end{array}$ & 5.409 & .024 \\
\hline
\end{tabular}

TABLE 3: Group 1 and Group 2 means for SWLS, INCOM, PA, NA, PCS-12 and MCS12 as well as follow-up ANOVAS for scales by group analysis. 
To address the main research question regarding differences between Group 1 and Group 2, a multivariate analysis of variance (MANOVA) was conducted to simultaneously assess for possible between group differences. Group membership (Group 1 or Group 2) was used as the independent variable with the results of participants' responses to the SF-12, INCOM, SWLS, and PANAS as dependent variables. This analysis yielded no overall effect for group membership (Wilks' Lambda $F(6,51)=1.919, p=.096)$, however significant effects were found for the use of social comparison (INCOM x group F $(1,56)=4.467, \mathrm{p}=.039)$, with Group 2 reporting greater use of social comparison as compared to Group 1. Additionally, a significant effect was found for level of mental health (MCS-12 x group $F(1,56)=5.409, p=.024$.) with Group 2 indicating significantly lower levels of mental health (higher emotional distress) as compared to Group 1. No other significant effects of group membership were found. These results are also shown in Table 3.

Specific hypotheses for the present study stated that physical health ratings would be significantly higher for Group 2 as compared to Group 1 due to increased healing time from injury, while Group 2 would have decreased mental health ratings due to increasing awareness of the possible permanence of disability. As indicated above, the hypothesis that significant differences would be found in reports of physical health between the two groups was not supported by the data (although Group 2 had non-significantly higher PCS-12 scores as compared to Group 1). Participants in Group 2 did have significantly lower MCS-12 scores as compared to Group 1, therefore the hypothesis that Group 2 would express significantly lower levels of mental health was supported. As 
hypothesized, no significant differences in reported levels of subjective well being (as evidenced by insignificant differences SWLS, PA and NA scores) were found between Group 1 and Group 2.

The next hypothesis was that the need for social comparison would be maintained at similar levels across both groups, however the direction of comparison (upward or downward), relative evaluation (positive emotional response to comparison or negative emotional response to comparison), and purpose for using comparison (to assess physical functioning or to seek information about coping) would differ between groups. Results above did not support the first part of this hypothesis, as mean INCOM scores were significantly higher for Group 2 as compared to Group 1.

To address the hypothesis regarding possible group differences in use of upward versus downward social comparison and associated positive versus negative emotional association with comparison, a 2x2x2 MANOVA was conducted. Group membership was the independent variable. Direction of social comparison (upward or downward) and emotion associated with comparison (positive or negative affect) were the dependent variables. The hypothesis was evaluated using a mixed design, with group membership as a between subjects variable and direction and emotion as within subjects variables. This analysis yielded no overall main effect for group membership $(F(1,56)=.564, p=.456)$ and no significant effects for direction (upward or downward) by group membership (1, 56)-.006, $\mathrm{p}=.940$ ), emotional association (positive or negative) by group membership $(\mathrm{F}(1,56)=1.854, \mathrm{p}=.179)$, or direction by emotion by group membership $(\mathrm{F}(1.56)=.006$, 
$\mathrm{p}=.940$.) While not significant, a slight trend towards increased negative affect associated with both upward and downward comparison was noted for Group 2 as compared to Group 1, while levels of endorsement of positive emotional response associated with comparison remained almost constant between the two groups (see Figure 1).

\section{Social Comparison Activity Between Groups}

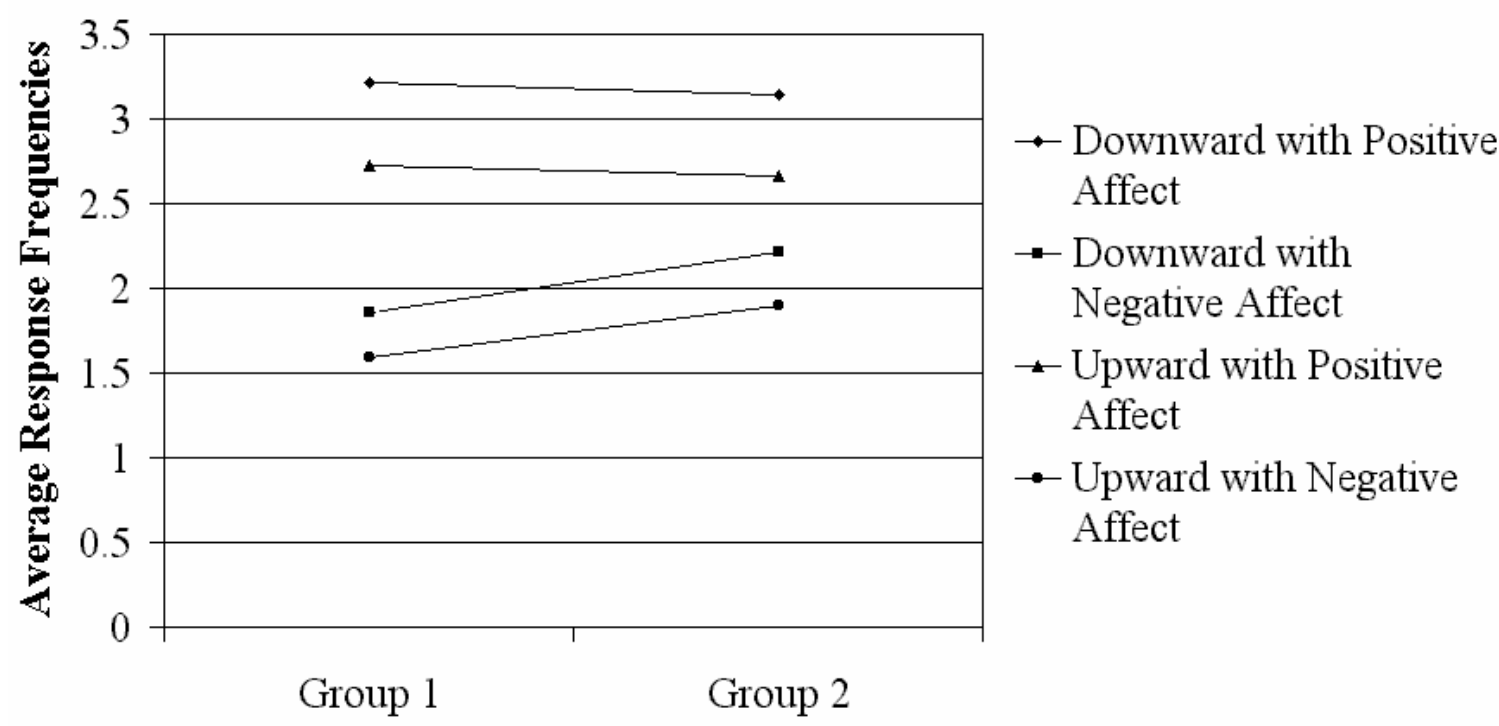

Figure 1: Line graph displaying Group 1 and Group 2 average response frequencies to four within-subjects questions regarding direction of comparison and emotion associated with comparison. $(\mathrm{n}=58)$. 
The open-ended questions asked to elicit information regarding the purpose for use of comparison (i.e. to compare regarding physical functioning versus to gain information regarding how others cope with disability) did not provide the anticipated information: It was found that many subjects did not respond to these questions at all, often indicating that they were unable to think of an example. The responses that were elicited were generally vague and difficult to categorize strictly as coping versus physical purposes for comparison. For this reason, statistical analysis could not be conducted regarding participants' purposes for using comparison.

An additional goal of analysis was to see how well the results of information gathered from this sample generally corresponded with the findings of Vanderzee and her colleagues (1996) in examining social comparison activity in a sample of cancer patients versus healthy controls. While the number of participants in the current study did not allow for a path analysis, as was conducted by Vanderzee and her colleagues (1996), correlations were computed for variables involved in the study and observed correlations are reported in Tables 4 and 5. Results of the current study indicate a significant negative correlation between physical health (distress) and emotional health (distress) (r= $-.703, \mathrm{p}<.01)$. A significant negative correlation was also found between mental health and an increased report of social comparison activity, $(\mathrm{r}=-.276, \mathrm{p}<.05)$, which suggests that a decline in mental health (reduced MCS-12 scores) would be positively correlated with increased reports of social comparison activity.

In expanding from Vanderzee et al. (1996) to include upward comparison as well as downward comparison, it was hypothesized that for Group 1, The need for social 
comparison would be positively correlated with downward comparison with associated positive affect. This hypotheses was not supported, as a significant correlation was not found $(\mathrm{r}=.146, \mathrm{p}>.05)$. For Group 2, it was hypothesized that the need for social comparison would be positively correlated with upward comparison with associated positive affect and also for social comparison downward with positive affect. This hypotheses also was not supported by the data $(r=.196, p>.05, r=.278, p>.05$, respectively.) While these correlations were not significant, it was shown that downward comparison associated with positive affect was used most frequently by both groups in the current study.

\begin{tabular}{ccccccccc}
\hline & PCS-12 & MCS-12 & INCOM & SWLS & PA & HEALTH & COPING & GENERAL \\
\hline PCS-12 & & & & & & & \\
MCS-12 & $-.703^{* *}$ & & & & & & \\
INCOM & .064 & $-.276^{*}$ & & & & & \\
SWLS & $.428^{* *}$ & -.099 & -.152 & & & & \\
PA & $.411^{* *}$ & -.103 & .026 & $.297^{*}$ & & & \\
HEALTH & .212 & -.159 & .079 & .171 & $.483^{* *}$ & & \\
COPING & .244 & -.018 & .115 & $.497^{* *}$ & $.318^{*}$ & $.465^{*}$ & & \\
GENERAL & .153 & .012 & .204 & $.337^{*}$ & $.322^{*}$ & $.309^{*}$ & $.549 * *$ & \\
NA & -.244 & -.161 & $.283^{*}$ & $-.486^{* *}$ & $-.317^{*}$ & $-.287^{*}$ & $-.492^{* *}$ & -.243 \\
\hline
\end{tabular}

Table 4: Total Group Correlations for comparison with VanderZee et al. (1996) model. (Note: $* p<.05 ; * * p<.01)$. 


\begin{tabular}{lccccccccrr}
\hline & \multicolumn{2}{c}{ INCOM } & \multicolumn{2}{c}{ SCDOWN+ } & \multicolumn{2}{c}{ SCUP+ } & \multicolumn{2}{c}{ SWLS } & PA \\
& G1 & G2 & G1 & G2 & G1 & G2 & G1 & G2 & G1 & G2 \\
INCOM & & & & & & & & & & \\
SCDOWN+ & .146 & .278 & & & & & & & & \\
SCUP+ & -.111 & .301 & .367 & .142 & & & & & & \\
SWLS & -.040 & -.258 & .016 & .007 & .257 & .111 & & & & \\
PA & -.216 & .359 & $.443^{*}$ & .312 & $.538^{* *}$ & .190 & .268 & .322 & & \\
NA & .240 & .239 & .025 & .166 & -.045 & .151 & $-.442^{*}$ & $-.540^{* *}$ & -.311 & -.273 \\
\hline
\end{tabular}

Table 5: Split Group Correlations for comparison with Vanderzee et al. (1996) model. (Note: $* p<.05 ; * * p<.01)$.

In addition, based on, but expanding the Vanderzee et al. (1996) model, it was hypothesized that appropriate social comparison activities at different times in recovery would be associated with positive measures of satisfaction with life. Specifically, for Group 1, it was hypothesized that downward comparison with associated positive affect for the purpose of evaluating physical functioning would be positively correlated with satisfaction with life and positive affectivity, and would be negatively correlated with negative affectivity. Despite the fact that we could not assess the purpose of comparison, the data for this study did not support the hypothesis of a significant positive correlation between downward social comparison with positive affect and satisfaction with life 
$(\mathrm{r}=.016, \mathrm{p}>.05)$, however a positive correlation with positive affectivity was found $(\mathrm{r}$ $=.443, \mathrm{p}<.05)$. A significant negative correlation between downward social comparison with positive affect and negative affectivity was not found $(r=.025, \mathrm{p}>.05)$. For Group 2 it was hypothesized that a significant positive correlation would be found between upward comparison with associated positive affect for the purpose of gaining coping information and satisfaction with life and positive affectivity, and a negative correlation would be found with negative affectivity. Downward comparison with positive affect for the purpose of comparing physical functioning would also produce positive correlations with satisfaction with life and positive affectivity. Results of analysis indicated that no significant correlations were found between these variables.

Within the present sample, significant correlations were not found between mental health, satisfaction with life, and/or positive affect. Physical health however was significantly positively correlated with positive affectivity $(\mathrm{r}=.441, \mathrm{p}<01)$ and satisfaction with life $(\mathrm{r}=.429, \mathrm{p}<.01)$. Mental health was not significantly correlated with participants' ratings of their health, coping, or general functioning as compared to others. Negative affectivity was found to be positively correlated with a need to compare $(\mathrm{r}=.283, \mathrm{p}<.05)$

To assess for group differences in response to questions in which participants rated their health, coping, and general functioning as compared to others with TBI, and also rated how they were doing compared to their perceptions of their physicians' prognosis for them early in recovery, univariate Analyses of Variance (ANOVAs) were conducted with group membership as the independent variable, and group means for participant responses to single questions ratings each of the above areas. A significant 
difference between Group 1 and Group 2 was found only in their responses to a question about how they would rate their recovery as compared to how their physicians told them they would be doing $(\mathrm{F}=(1,55)=4.074, \mathrm{p}=.048)$, with the mean for Group 1 significantly higher than the mean for Group 2 (as shown in Table 6.) The scores for each Group indicated that the average participant in Group 1 rated his or her recovery as "somewhat better" than predicted by the physicians, while the average participant in Group 2 rated his or her recovery as "about the same" as predicted by the physicians.

\begin{tabular}{ccccc}
\hline Factor & Means & $\mathrm{n}$ & $\mathrm{F}^{*}$ & $p$-value \\
\hline \multirow{3}{*}{ Health } & Group 1 $=4.26(\mathrm{SD}=.712)$ & 27 & .321 & .573 \\
& Group 2 $=4.14(\mathrm{SD}=.875)$ & 29 & & \\
Coping & Group 1 $=4.08(\mathrm{SD}=.935)$ & 26 & .287 & .594 \\
& Group 2 $=3.93(\mathrm{SD}=1.086)$ & 28 & & \\
General & Group 1 $=4.12(\mathrm{SD}=.909)$ & 26 & .012 & .915 \\
& Group 2 $=4.14(\mathrm{SD}=.639)$ & 29 & & \\
Physicians & Group 1 $=4.39(\mathrm{SD}=.832)$ & 28 & 4.074 & .048 \\
& Group 2 $=3.90(\mathrm{SD}=1.012)$ & 29 & & \\
\hline
\end{tabular}

Table 6: Between Group ANOVAs asking subjects to rate themselves compared to other TBI patients in terms of health, coping, and in general. In addition, participants were asked to rate how they were doing compared to their physicians' predictions for their recovery. $*(\mathrm{df}=1,56$ for all $)$. 
A Mann-Whitney Test was used to evaluate participants' responses to the CHART. This non-parametric test was chosen as the data were highly skewed, with the majority of scores falling towards the high end of the distribution. A significant difference between Groups was found only for the occupational subscale $(\mathrm{Z}=-2.169, \mathrm{p}=.030)$, with Group 2 reporting significantly higher scores. Group differences were not noted in subscales measuring physical independence $(Z=-1.148, p=.251)$, cognitive independence $(Z=-$ $.855, \mathrm{p}=.392)$, mobility $(\mathrm{Z}=-1.475, \mathrm{p}=.140)$, social integration $(\mathrm{Z}=-.296, \mathrm{p}=.767)$ or economic self-sufficiency $(Z=-.212, p=.832)$. Of note is that despite non-significant results, Group 2 reported higher levels of physical independence, cognitive independence, mobility and social integration. Group 2 reported slightly lower levels of economic selfsufficiency, although this measure is difficult to interpret due to a high level of missing data. A scale score on the CHART of 100 is considered to indicate functioning at a level of performance typical of a non-disabled individual. It should therefore be noted, as shown in Table 7 that neither Group 1 nor Group 2 attained mean

\begin{tabular}{llllllllll}
\hline & \multicolumn{3}{l}{ Group 1 } & \multicolumn{3}{l}{ Group 2 } & \multicolumn{5}{l}{ Total Group } \\
\hline & N & Mean & SD & N & Mean & SD & N & Mean & SD \\
Physical Independence & 29 & 74.07 & 39.48 & 29 & 87.62 & 28.06 & 58 & 80.84 & 34.63 \\
Cognitive Independence & 29 & 69.90 & 33.82 & 28 & 77.68 & 32.09 & 57 & 73.72 & 32.92 \\
Mobility & 29 & 76.70 & 18.77 & 28 & 82.75 & 19.19 & 57 & 79.68 & 19.05 \\
Occupation & 28 & 36.44 & 37.97 & 28 & 57.34 & 37.18 & 56 & 46.89 & 38.70 \\
Social Integration & 29 & 82.93 & 27.24 & 29 & 83.16 & 23.99 & 58 & 83.04 & 25.44 \\
$\begin{array}{l}\text { Economic Self- } \\
\text { Sufficiency }\end{array}$ & 21 & 79.89 & 27.45 & 14 & 72.93 & 32.35 & 35 & 77.11 & 29.25 \\
\hline
\end{tabular}

Table 7: Means and standard deviations for subscales of the CHART. 
scores of 100 on any subscale score. This suggests that despite some improvements reported by Group 2 in terms of mean levels of functioning at a later time from injury, as compared to Group 1, significant levels of disability remain across the domains measured for both groups.

Finally, some information was collected, regarding participants' frequency of interaction with others who have sustained brain injuries, as well as their interest in attending a support group, should one be available to them. This information is presented for Group 1, Group 2, and the Total Group in Table 8. For the Total Group, nine participants (15.5\%) indicated that they currently have contact with another person who has had a TBI, the remaining 49 participants $(84.5 \%)$ indicated that they did not. Only seven participants (12.1\%) reported attending a support group for individuals who have sustained a brain injury since release from the hospital, and only four participants indicated that they were currently attending. When asked to indicate the likelihood that they would attend a support group if one was available to them, 19 participants (32.8\%) reported "no likelihood", 12 participants (20.7\%) indicated "slight likelihood", six participants (10.3\%) reported feeling "unsure", 10 participants (17.2\%) reported "moderate likelihood", and seven participants (12.1\%) reported a "strong likelihood" of attending. The remaining four participants $(6.9 \%)$ did not respond to this question. 


\begin{tabular}{llll}
\hline & $\begin{array}{l}\text { Group 1 } \\
(\mathrm{n}=29)\end{array}$ & $\begin{array}{l}\text { Group 2 } \\
(\mathrm{n}=29)\end{array}$ & $\begin{array}{l}\text { Total Group } \\
(\mathrm{n}=58)\end{array}$ \\
\hline Have contact with another person with TBI. & $20.7 \%$ & $10.3 \%$ & $15.5 \%$ \\
Attended a support group since release from Rehabilitation & $13.8 \%$ & $10.3 \%$ & $12.1 \%$ \\
Of those who attended a support group, those still attending & $13.8 \%$ & $10.3 \%$ & $6.9 \%$ \\
Likelihood of attending a support group if offered: & & & \\
No likelihood & $27.6 \%$ & $37.9 \%$ & $32.8 \%$ \\
Slight likelihood & $27.6 \%$ & $13.8 \%$ & $20.7 \%$ \\
Unsure & $10.3 \%$ & $10.3 \%$ & $10.3 \%$ \\
Moderate Likelihood & $6.9 \%$ & $27.6 \%$ & $17.2 \%$ \\
Strong Likelihood & $17.2 \%$ & $6.9 \%$ & $12.1 \%$ \\
\hline
\end{tabular}

Table 8: Participant responses to questions regarding contact with others with TBI and support group participation. 


\section{CHAPTER 5}

\section{DISCUSSION}

Social comparison theory has been a part of psychology literature since it's introduction by Festinger in 1954, however there has been a surge of interest in this topic in recent years, and in particular there has been interest in the application of social comparison theory to health related concerns. (See for example, a recent text edited by B. P. Buunk \& F. X. Gibbons [1997] titled Health, Coping and Well Being: Perspectives from Social Comparison Theory). Over the past fifteen to twenty years, social comparison has been studied in individuals with health issues such as cancer (i.e., Bogart \& Helgeson, 2000; Wood, Taylor \& Lichtman, 1983; VanderZee, Buunk, DeRuiter, Tepelaar, VanSonderen \& Sanderman, 1996), chronic pain (i.e.,Affleck, Tennen, Urrows, Higgins \& Abeles, 2000), HIV disease (i.e., Bogart, Gray-Berhnhardt, Catz, Hartmann, \& Otto-Salaj,, 2002), heart disease (i.e., Helgeson \& Taylor, 1993), arthritis and infertility (i.e., Affleck, Tennen, 1991), as well as other health related issues, but little had been done to evaluate use of social comparison by individuals who have sustained brain injuries. The main purpose of the current study was to explore if and how individuals who have sustained traumatic brain injuries may make use of social comparison activity as part of the process of adjustment to disability during the first year post injury. 
It is widely accepted that this first year is a time of continued recovery. Therefore it could be expected that feelings of uncertainty may be present for individuals as they attempt to return to pre-injury levels of functioning, or adjust to the fact that they may be unable to do so. Based on the social comparison literature, it has been suggested that feelings of uncertainty may induce a greater need for comparing to others (i.e., Schacter, 1959), and that this comparison can be engaged in for different purposes at different times (i.e.,Lazarus \& Folkman, 1984; Taylor \& Lobel, 1989). In addition, it has been suggested that during periods of acute distress, individuals may tend to engage in downward comparison (comparing themselves to someone who is "worse off" as compared to themselves), and that selectively engaging in this sort of evaluation, allows the individual to feel more positively about his or her own situation (i.e., Taylor \& Lobel, 1989). If the situation causing the distress is persistent, it has been suggested that once the period of acute crisis is over, individuals may become interested in learning how to cope with their situation more effectively. At this point, the literature suggests that individuals may again feel uncertainty, but of a different sort ("how do I cope?"), and that this new uncertainty may cause them to shift to comparing themselves "upward" to someone whom they consider to be coping well under circumstances similar to their own (i.e., Wood and VanderZee, 1997; Taylor, 1983). It is argued that this sort of comparison selection may allow the individual to gain information about how to better his or her own situation, or to gain a sense of affiliation with a successful other (i.e., Taylor and Lobel, 1989). It has been suggested that by using social comparison appropriately, as described 
above, individuals both in acute and prolonged periods of distress may maintain a sense of subjective well-being (including satisfaction with life and positive affectivity) despite difficult circumstances (i.e., VanderZee et al., 1996).

With these ideas in mind, it was hypothesized in the present study that if individuals who have sustained brain injuries are engaging in social comparison activity, then the direction and purpose of these activities might change with time from injury. The current study was designed to explore two periods in the recovery process during which it was hypothesized that participants might be engaging in social comparison activity in different ways: within one month of discharge from inpatient rehabilitation, and at approximately six months post-discharge. These time periods were chosen because, although individuals throughout the first year of recovery following a brain injury may continue to experience both emotional and physical distress as the healing process progresses, it was thought that their may be a shift in adjustment during this time period: from the acute phase of getting out of the hospital and returning home having survived a life-threatening injury, to a later period during which there may be realization that some of the acquired disability may be long lasting or even permanent (that although they have survived, what was life-threatening is now life altering). The main hypotheses of this study therefore were focused on whether or not social comparison activity is used by persons with brain injury. Secondly, if comparison activity was found to be occurring, an attempt was made to examine the directions and purposes of these comparisons. In addition, the interactions between social comparison activity and subjective well being (including satisfaction with life and positive affect) were examined, as well as measures of physical and mental health and disability. Finally, participants were asked to rate their 
functioning compared to their perceptions of their physicians early predictions of their level of recovery and to rate their interest regarding participation in support groups.

The first hypothesis predicted that participants across both groups would express both physical and emotional distress, with no significant differences found in overall levels of distress. Results of the study indicated that participants in both groups expressed a significant amount of physical distress as compared to norms for the U.S. general population, but did not report mental distress significantly different from population norms. The CHART was used as an objective measure of functioning, and showed that both groups displayed significant levels of disability in terms of physical and cognitive functioning, mobility, occupation, social integration and economic independence as compared to non-disabled individuals. Interestingly, despite significant reports of disability and physical distress, total group ratings of satisfaction with life were reported at levels consistent with what has been found for the general population without injury. This absence of dissatisfaction suggests that there is some sort of mediating factor, which is allowing life satisfaction to be maintained despite significant difficulties in the first several months post-injury. The literature suggests that social comparison activity may be just such a factor (i.e.Vanderzee et al., 1996).

Considering group differences in physical and emotional functioning for the present sample, it was hypothesized that physical health scores would be significantly higher for Group 2 as compared to Group 1 due to increased healing time from injury. At the same time, it was hypothesized that Group 2 would express decreased levels of mental health due to increasing awareness of the possible permanence of some disability. Physical health scores were not significantly different between groups, suggesting that 
Group 2 continued to experience significant physical distress. Mental health scores were significantly lower for Group 2, as hypothesized, although not significantly lower than the norms for the U.S. general population. In looking at initial Glasgow Coma Scale (GCS) scores for Group 1 as compared to Group 2, the groups were very similar in terms of the numbers of participants with injuries rated to be in the mild, moderate and severe ranges. The apparent equivalence in injury severity suggests that the lack of significant improvement in physical functioning and the significant increase in mental distress is not due to Group 2 experiencing significantly more serious injuries. One suggested explanation for the reported increase in mental distress by Group 2 as compared to Group 1 , is that Group 1 may still feel "lucky", as they are still in a fairly early phase of their recovery, and may not yet anticipate difficulties in adjustment: It has been observed that patients often experience a "honeymoon" phase upon their release from the hospital. They express that they feel fortunate to have survived their injuries and report confidence in their ability to fully recover. In addition, very soon after discharge, they may have memories of others they encountered in the hospital who also experienced brain injuries. This may allow them to compare downward more readily with those who were injured more severely. Another consideration is that, there is likely to be less expectation for those who have just returned home from the hospital regarding return to work and engagement in activities at pre-injury levels. These reduced expectations are likely to be held by the individual as well as their family members. As a result, individuals closer to discharge may not immediately be faced with comparing temporally to themselves before injury or to others without disability. As time from injury increases however, uncertainty may increase if recovery of pre-injury roles and activities is not happening as quickly as 
expected, causing increased mental distress and inducing a greater need to compare in an effort to gain relief. The results indicate that participants in Group 2 are continuing to experience significant physical distress and disability across multiple domains, including social and occupational functioning at a time when they may be beginning to feel that they are no longer in "early" recovery. At six months post-rehabilitation, those in Group 2 may have expected that they would have made greater gains towards returning to work or would be closer to their pre-injury levels of functioning in other activities. As a result, they may be beginning to experience increased concern regarding the possible lasting effects of their injuries. Previous studies (i.e., Schacter, 1959) indicated that it is just such a period of uncertainty that may induce a greater need for social comparison.

The core finding of this study was that individuals who have sustained brain injuries do indeed express a need to compare to others at a rate comparable to other nonclinical populations studied. It was predicted that similar levels of reported need for social comparison would be expressed across both groups because, although physical distress was hypothesized to be greater for Group 1 and mental distress was hypothesized be greater for Group 2, it was thought that each type of distress would induce a need for each group to compare at similar levels. Contrary to the hypothesis, it was found that Group 2 expressed an increased need to compare, as compared to Group 1. When paired with the finding of Group 2's increase in mental distress, this fits with the assertion that periods of uncertainty may increase the need for comparison. As previously mentioned, the literature suggests that if the social comparison process is working effectively, individuals should maintain positive affect and satisfaction with life (i.e., VanderZee et al. 1996). While ratings of life satisfaction were not found to have eroded significantly for 
either group in this study, it should be noted that a non-significant tendency was found for an increase in negative affectivity for Group 2 as compared to Group 1 and that this increase in negative affectivity was noted with both upward and downward comparison. If we recall that satisfaction with life, positive affectivity, and negative affectivity have been suggested as separate constructs in the assessment of subjective well-being (i.e. Diener, Suh, Lucas \& Smith, 1999), then an increase in negative affectivity may signal the beginning of a reduction in subjective well-being. In addition, this tendency for increased negative affectivity when combined with the observed increase in levels of mental distress, could suggest that Group 2 was trying to use comparison activity to relieve distress, but not doing so effectively. In the literature, it is argued that depression may interrupt the ability of one to use social comparison activity (either upward or downward) effectively (Buunk, Collins, Taylor, Vanyperen \& Dakof, 1990). If it is the case that depressive emotions associated with adjustment to disability might be beginning to erode subjective well-being, it is possible that a significant changes in other factors associated with subjective well-being, such as decreased satisfaction with life, increased negative affectivity and decreased positive affectivity, would be found if subjects were observed at a later time then was assessed in the current study.

Another possible explanation for the current findings is that persons with brain injury have difficulty shifting from downward to upward comparison. In between the effective use of downward and upward comparison, there may be a point at which downward comparison is no longer working effectively, however an individual may not yet have learned to use upward comparison to his or her advantage. It may be that individuals prone to comparing may turn towards upward comparison when they need 
"more" than can be provided by comparing downward, however it is possible that there may be a gap between finding that downward comparison is no longer completely alleviating the anxiety, and realizing that upward comparison may provide some relief. For individuals who have sustained brain injuries, some additional challenges in shifting to upward comparison may be suggested. For example, it has been suggested that individuals who have sustained brain injuries may have a lack of awareness of deficits early in recovery (i.e., Sherer, Hart, Nick, Whyte, Thompson, \& Yablon, 2003), and that an increased awareness of deficits occurs gradually over the first several months of recovery (i.e., Dirette, 2002). It is possible that such a lack of awareness may not allow an individual to make use of comparison activity effectively. It is also known that limited abstract reasoning abilities may be an issue for some individuals recovering brain injury. This limitation could impede the person's ability to make use of a more abstract idea (i.e. "coping") for comparison and may cause them to continue to use more concrete comparison activity (i.e., "physical functioning" comparisons) despite the suggestion that after a period of time, such comparisons may have limitations in providing relief from uncertainty regarding recovery (i.e., Wood and VanderZee, 1997).

After evaluating the general need for social comparison activity, the next hypothesis in this study stated that downward comparison would be significantly more common in the group within one month post-discharge from rehabilitation, and would be primarily engaged in for purposes of evaluating physical functioning as compared to other persons with traumatic brain injury. Conversely, it was hypothesized that upward comparison would be significantly more common in the group within the sixth month post-discharge from rehabilitation, and would be engaged in primarily for gaining 
information about coping with disability. However, downward comparison may continue to be used by this group for comparison of physical functioning. No significant differences were found between groups regarding upward versus downward comparison and positive versus negative emotion associated with comparison. Descriptively, however, it was noted that downward comparison associated with positive emotional response was rated as occurring most frequently by both groups, which is consistent with the previous literature (i.e. VanderZee et al., 1996; Bogart \& Helgeson, 2000; Buunk, Collins, Taylor, Vanyperen \& Dakof, 1990). Social comparison upward with a positive emotional response was next in frequency of endorsement, followed by social comparison in a downward direction associated with negative emotional response. Social comparison upward associated with negative emotional response was endorsed least frequently. In addition, the greatest changes in responses between groups seemed to be an increase in negative emotion associated with both upward and downward comparison for Group 2 as compared to Group 1 (although these differences were not significant). These findings may again suggest that downward social comparison is not providing the same degree of relief for Group 2 as compared to Group 1, however upward comparison is not providing members of Group 2 with relief either. This may lend additional credence to the argument that either depression or another mediating factor is affecting their ability to gain relief from comparison in either direction, or that perhaps they have not yet learned to make use of upward comparison effectively.

Findings from previous studies have suggested that the affect associated with either upward or downward comparison can be affected by other factors. For example in a study with cancer patients, Buunk, Collins, Taylor, VanYpreren, and Dakof (1990) 
found that low self-esteem and low perceived control over their illness and symptoms were associated with negative affect in response to downward comparison. Those in the same group with low self-esteem were also more likely to experience negative affect with upward comparison. Buunk et al. (1990) asserted that finding that someone is doing better or worse than oneself can be "depressing", and reported that some of the cancer patients in their study expressed fear that they would not recover from their cancer when they compared downward with individuals for whom recovery was not occurring. Selfesteem and a sense of control appeared to be moderating factors in the tendency for subjects to feel threatened by comparisons in either direction. It is possible that Group 2 in the current study felt a decreased sense of control and shaken self-esteem arising from continuing to experience significant levels of disability contrary to their beliefs that they would be more fully recovered by a given point in time. If this is the case, it may be that these factors are affecting their ability to gain relief from social comparison activities.

Despite finding no overall differences between groups in direction of comparison and affect associated with comparison, it is interesting to note changes in response patterns between Group 1 and Group 2 by looking at changes in frequencies of response choices. These differences are displayed in Figures 2-5. For example, for the question "How often have you felt lucky or grateful when exposed to others who are doing worse off than you are?" $6.9 \%$ of respondents in Group 1 endorsed "never", $17.2 \%$ of respondents endorsed "rarely", $24.1 \%$ of respondents endorsed "sometimes", and $51.7 \%$ of respondents endorsed "often" (see Figure 2). In comparison, subjects in Group 2 responded to the same question in the following manner: $20.7 \%$ of respondents endorsed “never", $0 \%$ endorsed rarely, $24.1 \%$ endorsed sometimes, and 55.2\% endorsed "often". 
While the majority of both groups reported that they "often" or "sometimes" felt positive emotion associated with downward comparison, it seems that a greater number of participants in Group 2 "never" felt "lucky" when comparing downward. Similarly, as shown in Figure 3, in response to the question "How often have you felt fearful or anxious in response to others who are doing worse than you are?" a greater number of participants in Group 2 indicated that they "sometimes" or "often" feel "fearful" when comparing downward, again suggesting that the use of downward social comparison is not as effective for Group 2 as compared to Group 1. Not only was it found that Group 2 is not using upward comparison more frequently, as hypothesized, but the frequency charts suggest that a greater percentage of subjects in Group 2 as compared to Group 1 "sometimes" or "often" feel "frustrated or depressed" when exposed to others who are doing better (see Figure 4). Unexpectedly, despite insignificant differences reported between groups overall, a greater percentage of subjects in Group 2, as compared to Group 1, indicated that they "never" feel "inspired or comforted" when exposed to others who are doing better then themselves. Conversely, a greater percentage of subjects in Group 1 indicated that they "always" feel "inspired or comforted" (see Figure 5). 
"How often have you felt lucky or grateful when exposed to others who are doing worse than you?"

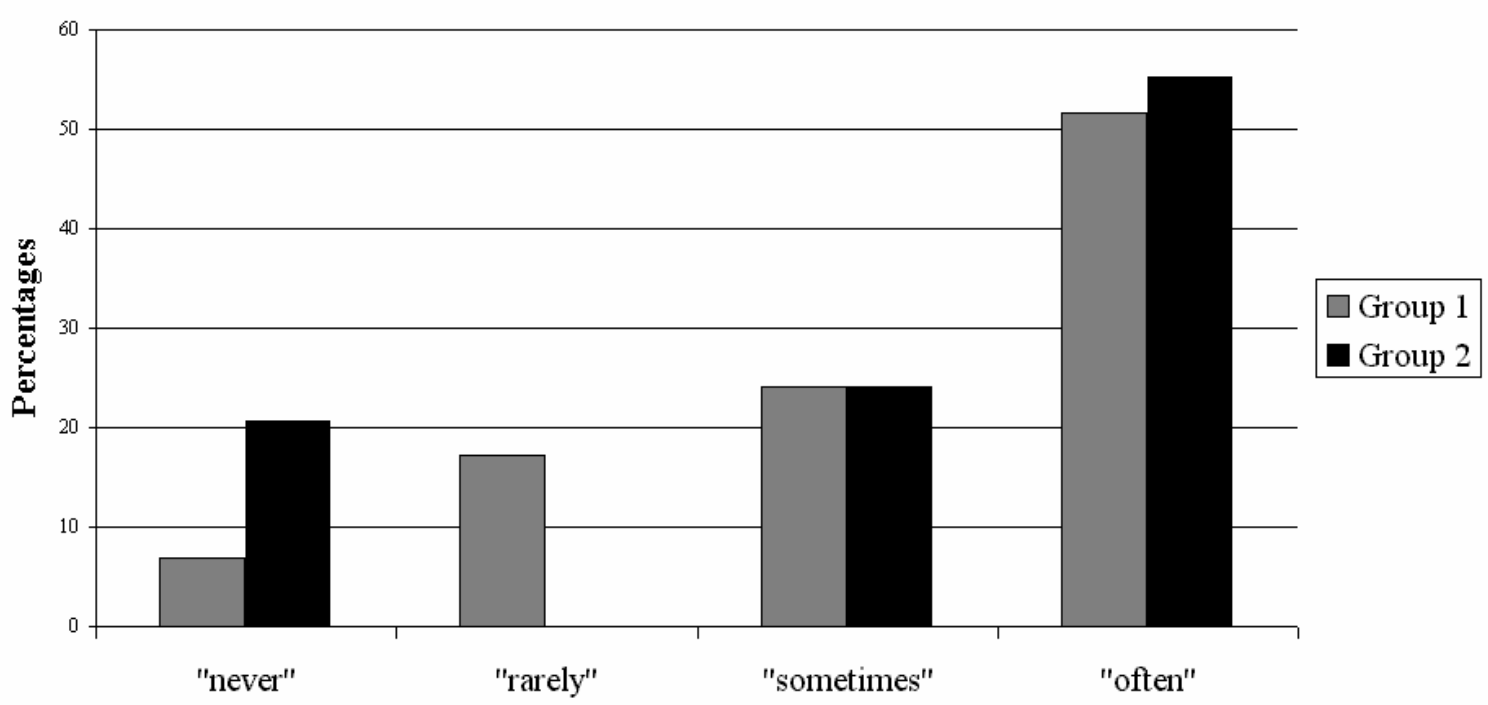

Figure 2: Bar graph displaying frequencies of Group 1 and Group 2 responses to question regarding downward social comparison with associated positive affect.

"How often have you felt fearful or anxious in response to others who are doing worse than you?"

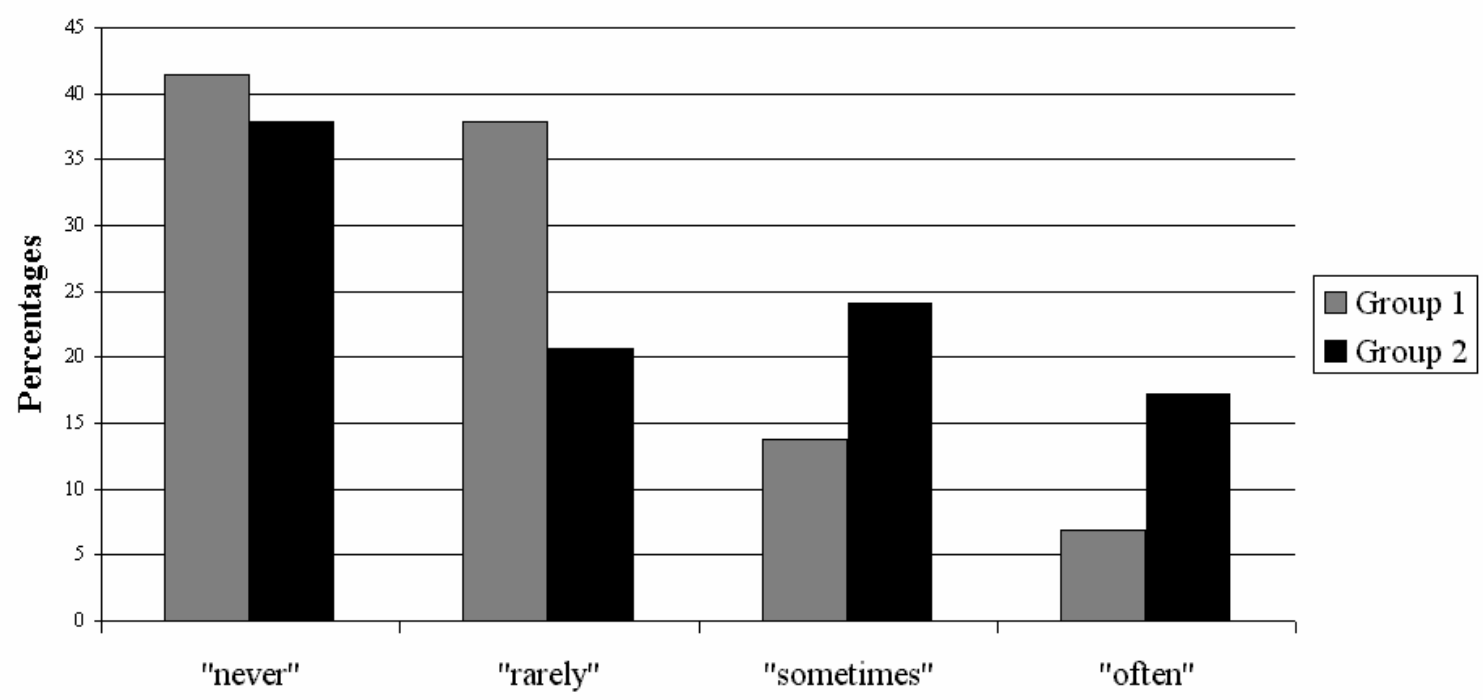

Figure 3: Bar graph displaying frequencies of Group 1 and Group 2 responses to question regarding downward social comparison with associated negative affect. 
"How often have you felt frustrated or depressed when exposed to others who are doing better than you are?"

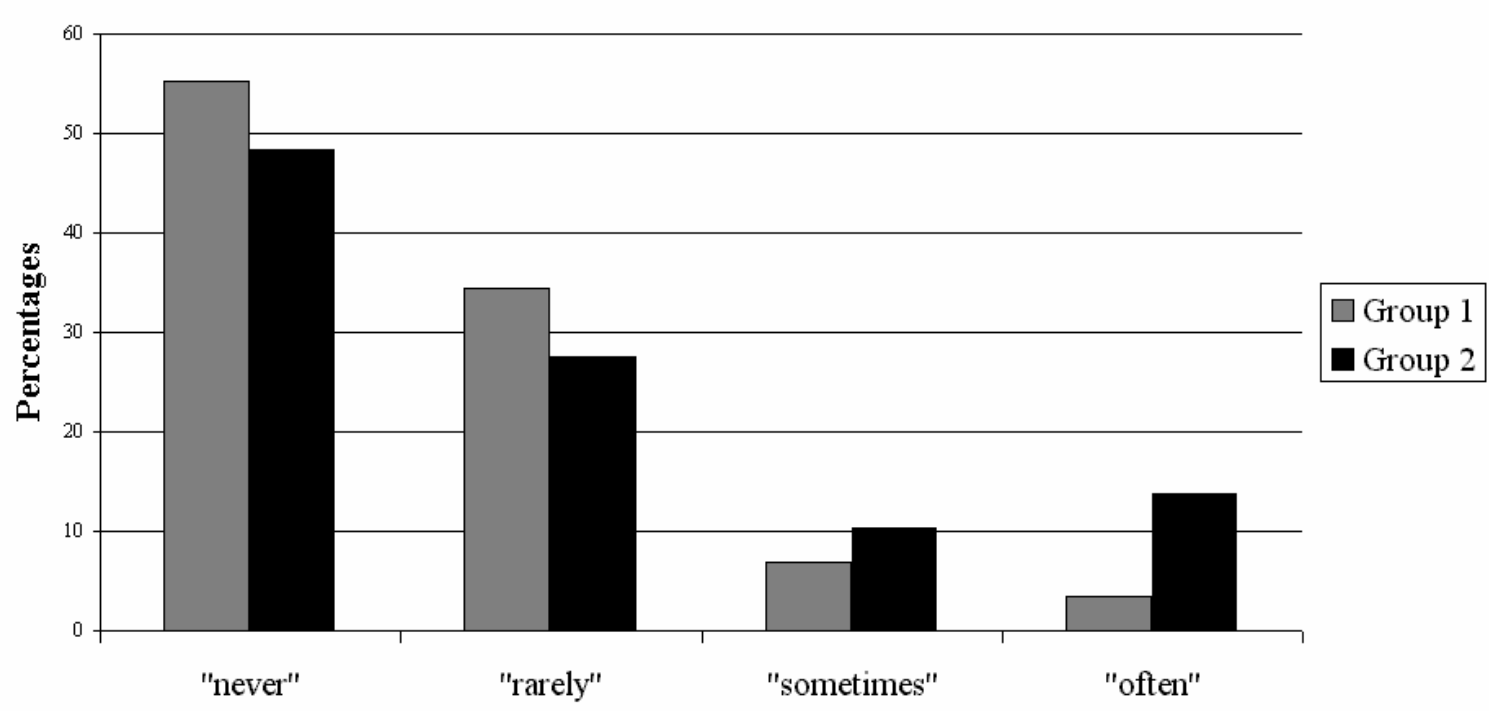

Figure 4: Bar graph displaying frequencies of Group 1 and Group 2 responses to question regarding upward social comparison with associated negative affect.

"How often have you felt inspired or comforted when you see others who are doing better than you are?"

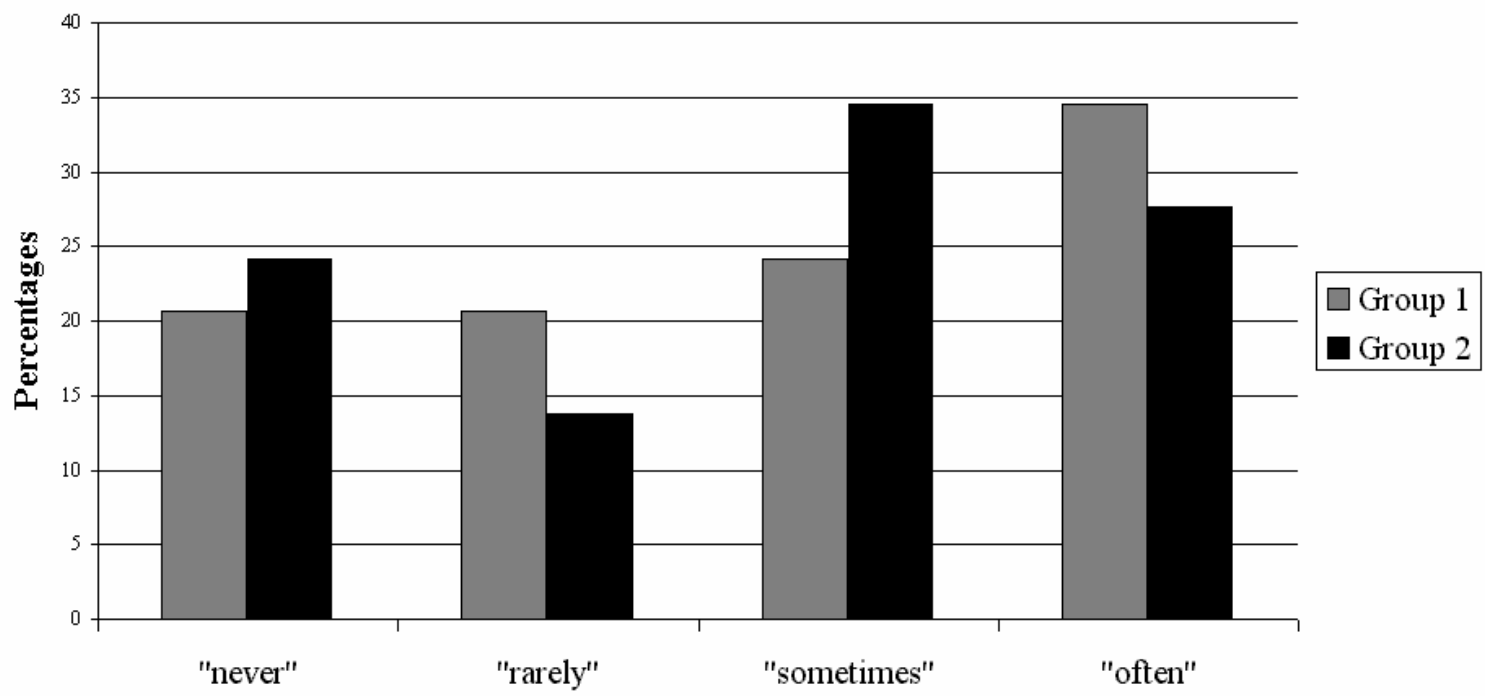

Figure 5: Bar graph displaying frequencies of Group 1 and Group 2 responses to question regarding upward social comparison with associated positive affect. 
These results seem to further suggest that an increased number of subjects in Group 2 as compared to Group 1 are unable to make use of downward comparison to relieve uncertainty, and some may even feel threatened by downward comparison. At the same time, upward comparison also does not appear to be providing relief, and may also be threatening to some subjects in Group 2. Related to the increased anxiety that Group 2 may be experiencing due to concerns about the lasting effects from their injuries, it may be that comparison is threatening due to the emotional risks of association with others with disabilities. Previous studies have suggested that sometimes people do not want to compare downward if they fear finding similarities between themselves and undesirable traits in those in the downward group (i.e., Thronton \& Arrowood, 1966). In the current study, if subjects had not yet identified themselves as permanently disabled, then comparing upward may involve comparison to themselves prior to injury, or to other nondisabled individuals rather than to persons with disabilities who is coping well. It may be easy to compare in either direction and achieve positive affect if one feels certain that they will fully recover from their injuries. However it is possible that if people are at a stage of adjustment in which they are just realizing but have not yet accepted their disability, then comparing in either direction may be threatening and may produce negative affect. In addition, if we consider that only three of the 29 participants in Group 2 indicated that they had contact with another person with a TBI, it is also possible that, despite an increased need for comparison, individuals further out from injury just do not have the opportunity to do so. It seems that further study into the evaluation of an individual's identification with a particular group (i.e., having a lasting or permanent 
disability), as well as the opportunities for comparison may be important to consider in looking at social comparison activity, and in evaluating support programs for individuals with TBI.

Another important factor may be related to the idea of "unrealistic optimism" as suggested by Weinstein and his colleagues (a review can be found Klein \& Weinstein, 1997), which seems to be akin to the "honeymoon phase" often observed in persons with traumatic brain injury around the time of release from rehabilitation. This construct describes the tendency for individuals to feel that they are less vulnerable than most other individuals to negative events. Results of this study may indicate that hopeful "overestimation" regarding the ability to return to premorbid levels of functioning may act similarly to unrealistic optimism, and may result in a difficult period of adjustment as the lasting effects of injury become more evident.

The next step in the current study was to look beyond direction of comparison to evaluate the purposes for which subjects might be making use of comparison. Based on the previous literature, it was hypothesized that Group 1 would engage in comparison activity primarily for purposes of evaluating physical functioning. Conversely, it was hypothesized that Group 2 would engage in comparison primarily for gaining information about coping with disability; however that downward comparison may continue to be used by this group for comparison of physical functioning. Unfortunately, due to a lack of interpretable data, analyses of the differences between groups could not be completed. The purpose of comparison was to be evaluated by coding participants' responses to follow-up questions to items about upward versus downward comparison: After being asked a general question about how frequently they experience positive or negative 
emotion related to upward or downward comparison (a total of four questions covered all options), participants were asked to give an example of a time in which they experienced the target emotion while engaged in the targeted directional comparison. It was found that many participants did not give an example or said that they could not think of one. Participants who did respond to this question generally gave vague responses. These responses were unable to be specifically coded as comparing to physical functioning versus for the purposes of gaining coping information. It is unfortunate that this information was not gathered in a way that could have been more effective at categorizing participant responses. It will be necessary to discern a way to restructure these questions in a more effective manner so that information may be elicited in order to gain a better understanding of this issue. It may be noteworthy to mention that $84.5 \%$ of participants indicated that they did not currently have contact with another individual with TBI. It is possible that this lack of contact could have made it more difficult to come up with examples of comparison activity. Some previous studies have used more directive methods of evaluating comparison activity (i.e., providing descriptions of comparison targets and asking more direct questions about comparison activity, or inducing upward or downward comparison purposefully). If information cannot be elicited spontaneously, it may be necessary to find a method of providing additional cueing to participants or asking specific follow-up questions in order to gain explicit information about the purpose of comparison activity.

A final goal of analysis was to see how well the results of information gathered from this sample corresponded with the findings of VanderZee and her colleagues (1996) in examining social comparison activity in cancer patients and healthy controls. As 
hypothesized for the present sample, a significant negative correlation was found between physical health and mental health, which is in direct contrast to the findings of VanderZee et al. (1996), who found a significant positive relationship between these factors. These differences were expected and are possibly due to differences in circumstances between cancer patients and persons with brain injury: For example, decreases in physical symptoms for a cancer patient might generally correspond with success in treatment and greater chance of remission or cure, which is likely to decrease emotional distress and uncertainty. In contrast, for those who have sustained brain injuries, we have described a tendency for a lack of awareness of deficits and/or an initial tendency for overestimation of one's ability to return to premorbid levels of functioning quickly and completely. For these reasons, despite continued healing, there is a greater likelihood that those who have sustained traumatic brain injury will experience increased emotional distress as they discover that healing, while occurring, is not happening as they initially expected. Results of the current study found an implied positive relationship between mental distress and need for social comparison, which seems to support VanderZee's et al. (1996) conclusion that emotional distress induced a need for social comparison. However, the ability to determine causation was beyond the scope of the current study. The findings of the current study fail to conform to the VanderZee's et al. (1996) model in the sense that significant correlations were not found between appropriate social comparison activity with positive affectivity and satisfaction with life. Within the present sample, significant correlations were also not found between mental 
health, satisfaction with life, and/or positive affect, as was found by VanderZee and her colleagues (1996). Physical health however was positively correlated with positive affectivity and satisfaction with life, matching the model.

These findings may again suggest that individuals who have sustained brain injury are not able to make use of comparison activity as effectively as individuals with other types of significant medical issues. The reasons for these differences are unclear. Given the positive correlation between physical health and positive affectivity as well as satisfaction with life, it may be asserted that the overall focus of the subjects continued to be on physical functioning, and that downward social comparison was the most appropriate form of comparison. It appears, however that for Group 2, as emotional distress increased (possibly due to increased awareness of deficits or slower than expected physical recovery), the need for social comparison activity increased as well. While satisfaction with life remains intact, the fact that negative affectivity showed a trend toward increasing suggests that social comparison activity may not be as able to maintain positive emotion and satisfaction with life as was found for cancer patients. While causality cannot be determined, the findings of the current study do not contradict the results of VanderZee et al. (1996) suggesting that distress may be inducing the need for comparison. However in the present study, comparison did not appear to be producing the desired effect as significantly as it did for the participants in VanderZee et al.'s (1996) study. Both groups maintained satisfaction with life scale scores within the normal range, however significant positive correlations connecting comparison activity 
with satisfaction with life were not found. In fact, as comparison activity increased, negative affectivity increased as well (possibly suggesting decreasing subjective wellbeing).

The finding that participants in Group 2 showed a significant decrease in their ratings of how they felt they were doing compared to their perceptions of the physicians' early predictions of their recovery could be explained in a couple of ways: It may be that if the members of Group 2 are feeling less positive, they may have more negative perceptions of their physicians' predictions for recovery (as suggested by Wheeler \& Miyake, 1992). In addition, it may be that an increase in awareness of deficits may allow them to be more realistic in their perceptions. It does appear, however that in addition to comparing to other patients, individuals who have sustained brain injuries seem to consider their doctors' predictions as part of the comparison process. Interestingly, despite significant differences between Group 1 and Group 2, neither group reported to be functioning at levels lower than predicted by their physicians, as the average scores remained in the "somewhat better" (Group 1) and "about the same" (Group 2) rating levels.

One of the reasons for exploring the possible uses of social comparison by individuals who have sustained brain injuries was to see if there was a need to provide opportunities for social comparison through support groups or other types of programs. Only $15.5 \%$ of participants in the current study indicated that they currently had contact with another individual who has sustained a brain injury, and only $6.9 \%$ indicated that they were currently attending a TBI support group. As indicated in Figure 6, when this was broken down by group, only $10.3 \%(n=3)$ of individuals in Group 2 indicated that they had contact with another person who had sustained a TBI as compared to $20.7 \%$ 
$(n=6)$ of participants in Group 1. Individuals in Group 1 were also more likely to be attending a support group as compared to Group 2. When asked about their likelihood of attending a support group should one be available to them, a total of 53.5\% participants indicated that there would be "no" or "slight" likelihood that they would attend a group, while $10.3 \%$ reported to be "unsure" and $29.3 \%$ indicated that a "moderate" to "strong" likelihood of attending. Even if all of those who reported to be "uncertain" were placed in the group who expressed an interest in attending, the majority would still remain at best "slightly interested." Frequencies of Group 1 and Group 2 interest in group attendance is shown in Figure 7. There was an $8.8 \%$ overall increase in reported interest in attending a support group for Group 2 as compared to Group 1, although the majority of Group 2 (53.6\%) continued to report "no" or "slight" interest in attending. 


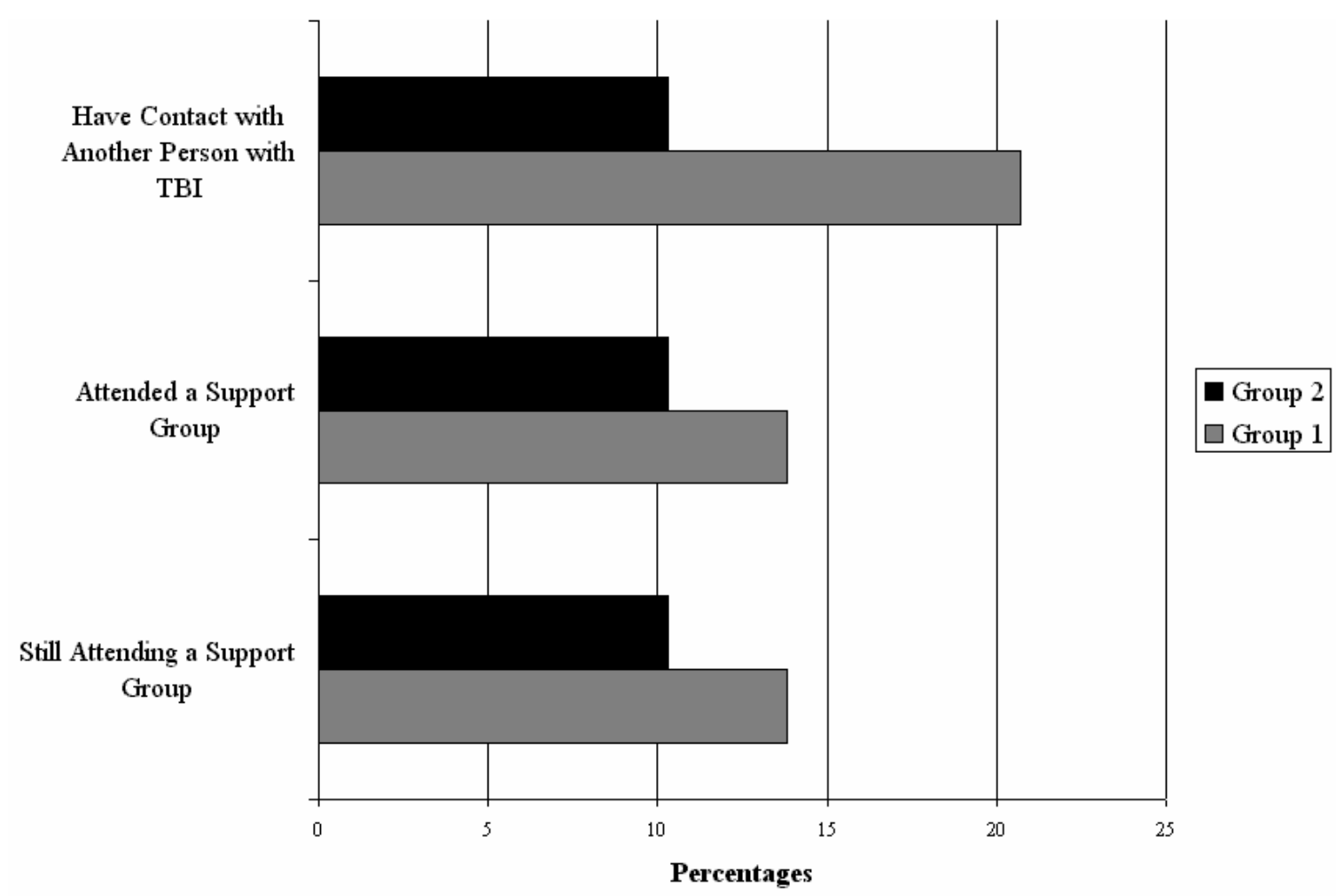

Figure 6: Bar graph displaying percentages of Group 1 and Group 2 participants indicating that they currently have contact with another person with TBI, have attended a support group since release from rehabilitation, and if so, are still attending. 
"What is the likelihood that you would attend a support group if one were available at this time?"

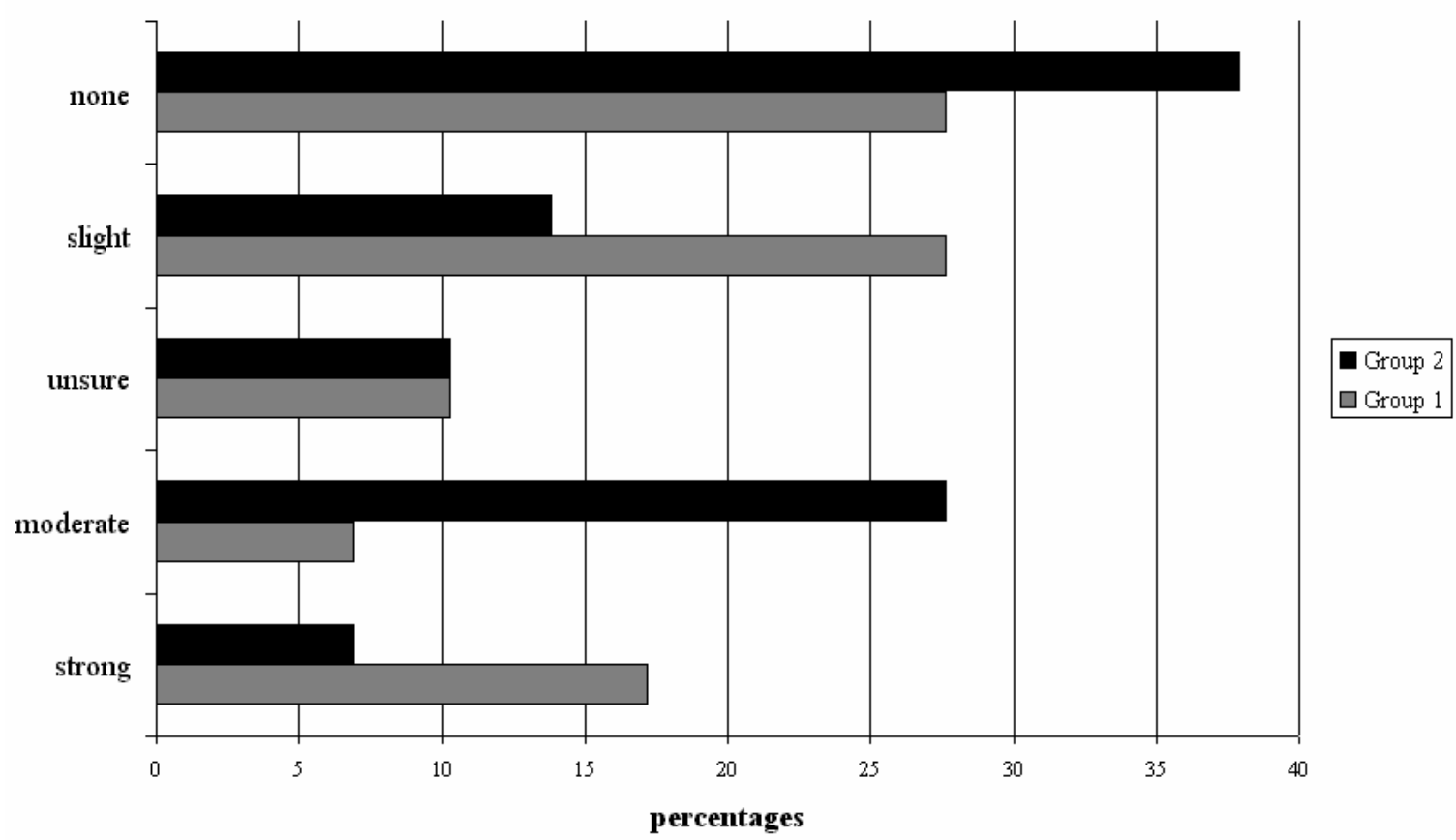

Figure 7: Bar graph displaying Group 1 and Group 2 frequencies of responses to a question about the likelihood of attending a support group.

These results suggest that despite reporting increases in need for comparison and little opportunity for comparison, the majority of participants in Group 2 continue to report little or no interest in attending a support group. Subjects may have a reluctance to associate or identify with others with traumatic brain injury, as previously described. In addition, the literature presents evidence that individuals respond negatively to direct confrontation with others who are worse off (i.e. with cancer patients in VanderZee, Buunk, and Sanderman, 1998), especially if one is concerned that their own condition 
may deteriorate (Buunk, Collins, Van Yperen, Taylor, \& Dakoff, 1990). It seems that individuals in such situations may be more interested in learning about others who are worse off, than in directly confronting them. While those who have sustained brain injuries are less likely to experience health deterioration as compared to cancer patients, there may be reluctance to identify with others with disability during a period when the individual has not yet accepted the lasting effects of their illness. The literature indicates a greater preference by individuals in other populations to learn about and affiliate with others who are better off and are coping well (i.e., Buunk, 1995). For those who have sustained brain injuries, however, there may also be a reluctance (or inability) to compare upward effectively if one is not yet identifying with others who have sustained brain injuries. In this situation, upward comparison would likely involve comparing to a preinjury self or another person without disability, rather than a well-functioning person with a similar disability. For this reason, it is likely that upward comparison would not result in positive self-assessment. Alternately, given that only three out of 29 individuals in Group 2 indicated that they currently had contact with another person with TBI, it is also possible that individuals in this group have just not had any opportunity to interact with an individual who is further in recovery and can be a positive role model for upward comparison. If this is the case, then a reluctance for support group participation may be due to a lack of awareness that there may be others further from injury who may be able to provide the coping information which may be of interest. Regardless of the reasons, the findings of the current study, paired with the previous literature regarding support groups and the effects of depression on the ability to use comparison activity effectively, suggest that it may be very important to assess the current emotional status of patients 
prior to placing them in support groups. In addition, it may be essential, especially with persons with brain injury, to assess their level of adjustment to disability and corresponding level of identification with other individuals with disabilities. These suggestions would be important areas for further study.

Given the exploratory nature of the current study, there are several limitations that need to be acknowledged and may be addressed in future studies. The sample size of 58 is a limiting factor. Ideally the use of a larger sample size would provide greater power and would have allowed for additional analysis (for example, a replication of the path analysis conducted by VanderZee and her colleagues, 1996). As little work has been done in this area with individuals who have sustained brain injuries, differences in demographic variables and response norms between persons with traumatic brain injury and other groups with different medical concerns may limit the ability to compare groups easily (for example, this population is predominantly male, and much of the social comparison research for cancer patients has been focused on females with breast cancer). In addition, differences in adjustment issues between persons with traumatic brain injury and individuals with other medical issues may affect the ability to compare between groups. Further assessment of cognitive issues related to brain injury (i.e., lack of awareness, limitations in memory, or abstract reasoning) may need to be examined in relationship to social comparison. It also would be helpful to be able to conduct longitudinal rather than cross-sectional studies of the use of social comparison by individuals who have sustained brain injuries. Such a design would allow for true assessment of changes over time, rather than comparing between groups at different times. As previously indicated, the purposes of comparison used could not be evaluated 
in the present sample due to a lack of interpretable data. This information would be an interesting area for future study. In addition, it appears that the two groups observed in the current study were beginning to show some differences in emotional functioning and use of social comparison activity, however it may be helpful to look at groups even further post-injury. It is hypothesized that if later groups were examined, even greater differences between groups would be found. These more significant differences may clarify the ways in which individuals who are working to adjust to disabilities resulting from brain injury use social comparison.

Given that 80,000 to 90,000 individuals in the United States experience the onset of significant long-term disability due to traumatic brain injury each year (Center for Disease Control and Prevention, 2001), it seems that learning more about the adjustment to disability process for these individuals may be an important aspect of helping them to reach their potential for optimal functioning. The purpose of the present study was to explore social comparison process as a possible mediating factor in the adjustment to disability process. It seems, based on the results of the current study, that individuals who have sustained traumatic brain injuries may make use of social comparison to maintain subjective well-being with some success, at least early in recovery. It appears that there may be factors that reduce the effectiveness of social comparison activity as time postinjury progresses. Several limiting factors and suggestions for further consideration have been identified, and may be addressed in future studies. 


\section{REFERENCES}

Affleck B. \& Tennen, H. (1991). Social comparison and coping with major medical problems. In J. Suls \& T. A. Wills (Eds.) Social Comparison: Contemporary Theory and Research. (pp. 369-393). Hillsdale, N.J.: L. Erlbaum Associates.

Affleck, B. , Tennen, H., Pfeiffer, C., Fifleid, J., \& Rowe, J. (1987). Downward comparison and coping with serious medical problems. American Journal of Orthopsychiatry, 57, 570-578.

Affleck, B., Tennen, H. Urrows, S., Higgins, P. \& Abeles, M. (2000). Downward comparisons in daily life with chronic pain: Dynamic relations with pain intensity and mood. Journal of Social and Clinical Psychology, 19(4), 499-518.

Blalock, S. J., Devellis, B. M., \& DeVellis, R. F. (1989). Social comparison among individuals with rheumatoid arthritis. Journal of Applied Social Psychology, 19(8), 665-680.

Bogart, L. M., \& Helgeson, V. S. (2000). Social comparisons among women with breast cancer: A longitudinal investigation. Journal of Applied Social Psychology, 30(3), 547-575.

Bogart, L. M, Gray-Bernhardt, M. L., Catz, S. L., Hartmann, B. R., \& Otto-Salaj, L. L. (2002). Social and temporal comparisons made by individuals living with HIV disease: Relationships to adherence behavior. Journal of Applied Social Psychology, 32(8), 1551-1576.

Brickman P., \& Bulman, R. J. (1977). Pleasure and pain in social comparison. In J. M. Suls \& R. L. Miller (Eds.), Social Comparison process: Theoretical and empirical perspectives (pp. 149-186). Washington DC: Hemisphere.

Burnett, D. M., Kolakowsky-Hayner, S. A., Slater, D., Stringer, A.,Bushnick, T., Zafonte, R., \& Cifu, D. X. (2003). Ethnographic analysis of traumatic brain injury patients in the National Model Systems Database. Archives of Physical Medicine and Rehabilitation, 84, 263-267.

Buunk, B. P. (1994). Social comparison processes under stress: Towards an integration of classic and recent perspectives. In Stroebe \& M. Hewstone (Eds.), European Review of Social Psychology, (Vol 5, pp. 211-241). Chichester: Wiley. 
Buunk, B. P. (1995). Comparison direction and comparison dimension among disabled individuals: Toward a refined conceptualization of social comparison under stress. Personality and Social Psychology Bulletin, 21(4), 316-330.

Buunk, B. P.\& Brenninkmeijer, V. (2001). When individuals dislike exposure to an actively coping role model: Mood change as related to depression and social comparison orientation. European Journal of Social Psychology, 31,(5), 537-548.

Buunk, B. P., Collins, R. L., Taylor, S. E., VanYperen, N. W., \& Dakof, G. A. (1990). The affective consequences of social comparison: Either direction has its ups and downs. Journal of Personality and Social Psychology, 59(6), 1238-1249.

Buunk, B. P., Gibbons, F. X., \& Reis-Bergan, M. (1997). Social comparison in health and illness: An overview. In B.P. Buunk and F. X. Gibbons (Eds.), Health, coping and well-being: Perspectives from social comparison theory. Mahwah, N.J.: Lawrence Erlbaum Associates, Inc.

Buunk, B. P., Gibbons, F. X., \& Visser, A. (2002). The relevance of social comparison processes for prevention and health care. Patient Education and Counseling, 47(1), 1-3.

Buunk, B. P., \& Schaufeli, W. B. (1993). Professional burnout: A perspective from social comparison theory. In W. B. Schaufeli, C. Maslach, \& T. Marek (Eds.), Professional burnout: Recent developments in theory and research. New York: Hemisphere.

Buunk, B. P., VanYperen, N. W., Taylor, S. E., \& Collins, R. L. (1991). Social comparison and the drive upward revisited: Affiliation as a response to marital stress. European Journal of Social Psychology, 21, 529-546.

Center for Disease Control and Prevention (n.d.). Traumatic brain injury facts NCIPC. Retrieved April 18, 2003 from http://www.cdc.gov/ncipc/factsheets/tbi.htm.

Corrigan, J. D., Bogner, J. A., Misiw, W. J., Clinchot, D., \& Fugate, L. (2001). Life satisfaction after traumatic brain injury. Journal of Head Trauma Rehabilitation, 16 (6), 543-555.

Deiner, E., Emmons, R. A., Larsen, R. J., \& Griffin, S. (1985). The Satisfaction With Life Scale. Journal of Personality Assessment, 49(1), 71-85.

Diener, E., Suh, E. M., Lucas, R. E., \& Smith, H. L. (1999). Subjective wellbeing: Three decades of progress. Psychological Bulletin, 125(2), 276-302.

Dirette, D. (2002). The development of awareness and the use of compensatory strategies for cognitive deficits. Brain Injury, 16(10), 861-871. 

117-140.

Festinger, L. (1954). A theory of social comparison process. Human Relations, 7,

Gibbons, F. X. (1986). Social comparison and depression: Company's effect on misery. Journal of Personality and Social Psychology, 51, 1-9.

Gibbons, F. X., \& Buunk, B. P. (1999). Individual differences in social comparison: Development of a scale of social comparison orientation. Journal of Personality and Social Psychology, 76(1), 129-142.

Gibbons, F. X., Lane, D. J., Gerrard, M., Reis-Bergan, M., Lautrup, C. L., Pexa, N. A., \& Blanton, J. (2002). Comparison-level preferences after performance: Is downward comparison still useful? Journal of Personality and SocialPsychology, 83(4), 865-880.

Hackmiller, K. L. (1966). Threat as a determinant of downward comparison. Journal of Experimental Social Psychology, (Suppliment 1), 32-39.

Helgeson, V. S., \& Taylor, S. E. (1993). Social comparisons and adjustment among cardiac patients. Journal of Applied Social Psychology, 23(15), 1171-1195.

Hyman, H. (1942). The psychology of subjective status. Psychological Bulletin, 39, 473-474.

Klein, W. M. \& Weinstein, N. D. (1997). Social comparison and unrealistic optimism about personal risk. In B. P Buunk \& F. X.Gibbons (Eds.), Health, coping, and well-being: Perspectives from social comparison theory. Mahwah, N.J.: Lawrence Erlbaum Associates, Inc.

Lane, D. J., Gibbons, F. X., Gerrard, M., Blanton, H. \& Buunk, B. P. (2002). Comparison strategies in response to threat: When does social comparison make a difference. Advances in Psychology Research, 10, 71-97.

Lazarus, R. S., \& Folkman, S. (1984). Stress, appraisal and coping. New York: Springer-Verlag.

Max, W., Mackenzie, E. J., \& Rice, D. P. (1991). Head injuries: Costs and consequences. Journal of Head Trauma Rehabilitation, 6(2), 76-91.

Rimel, R. W., Giordani, B., Barth, J. T. \& Jane, J. A. (1982). Moderate head injury: Completing the clinical spectrum of brain trauma. Neurosurgery, 11(3), 344-351.

Rolfe, Y. (1984). Stress and affiliation: A utility theory. Psychological Bulletin, $91,235-250$. 
Schacter, S. (1959). The psychology of affiliation. Palo Alto, CA: Stanford University Press.

Sherer, M., Hart, T., Nick, T. G., Whyte, J, Thompson, R. N., and Yablon, S. A. (2003). Early impaired self-awareness after traumatic brain injury. Archives of Physical Medicine and Rehabilitation, 84, 168-176.

Sherif, M. A. (1936). The psychology of social norms, New York: Harper.

Stouffer, S. A., Suchman, E. A., De Vinney, L. C., Star, S. A., \& Williams, R. M. Jr. (1949). The American soldier: Adjustment during army life. (Vol 1). Princeton N.J. Princeton University Press.

Taylor, S. E. (1983). Adjustment to threatening events. American Psychologist, 38, 1161-1173.

Taylor, S. E. \& Loebel, M. (1989). Social comparison activity under threat: Downward evaluation and upward contacts. Psychological Review, 96(4), 569-575.

Taylor, S. E., Wood, J. V., C\& Lichman, R. R. (1983). It could be worse: Selective evaluation as a response to victimization. Journal of Social Issues, 39(2), 19-40.

TBI Model Systems National Database (2002). Data from the traumatic brain injury model system. Traumatic Brain Injury: Facts and Figures Newsletter (8)1, Winter 2002. Retrieved April 2, 2003 from http//:www.tbindc.org.

Thornton, D. A. \& Arrowood, A. J. (1966). Self-evaluation, self-enhacement, and the locus of social comparison. Journal of Experimental Social Psychology Supplement, $1,40-48$.

VanderZee, K. I., Buunk, B. P., DeRuiter, J. H. , Tempelaar, R., Van Sonderen, E., \& Sanderman, R. (1996). Social comparison and the subjective well-being of cancer patients. Basic and Applied Social Psychology, 18(4), 453-468.

VanderZee, K. I. , Buunk, B. P., \& Sanderman, R. (1996). The relationship between social comparison processes and personality. Journal of Personality and Individual Differences, 20(5), 551-565.

Ware, J. E,. Kosinski, M., and Keller, S. D. (1995). SF-12: How to score the SF12 physical and mental health summary scales. Boston MA: The Health Institute, New England Medical Center, Second Edition.

Watson, D., Clark, L. A., \& Tellegen, A. (1988). Development and validation of brief measures of positive and negative affect: The PANAS scales. Journal of Personality and Social Psychology, 54(6), 1063-1070. 
Wheeler L., \& Miyake, K. (1992). Social comparison in everyday life. Journal of Personality and Social Psychology, 62( 5), 760-773.

Whiteneck, G. G., Charlifue, S. W., Gerhart, K. A., Overhosler, J. D., \& Richardson G. N. (1992). Quantifying handicap: A new measure of long-term rehabilitation outcomes. Archives of Physical Medicine and Rehabilitation, 73, 519-526.

Wills, T. A. (1981). Downward comparison principles in social psychology, Psychological Bulletin, 90(2), 245-271.

Wood, J. V., Michela, J. L \& Giordano, C. (2000). Downward comparison in everyday life: Reconciling self-enhancement models with the mood-cognition priming model. Journal of Personality \& Social Psychology, 79 (4), 563-579.

Wood, J. V., Taylor, S. E., \& Lichtman, R. R. (1985), Social comparison in adjustment to breast cancer, Journal of Personality and Social Psychology, 49(5), 11691183.

Wood, J. V., \& VanderZee, K. (1997). Social comparisons among cancer patients: Under what conditions are comparisons upward and downward. In B. P. Buunk \& F. X. Gibbons (Eds.), Health, coping, and well-being: perspectives from social comparison theory. Mahwah, NJ: Lawrence Erlbaum Associates.

Ybema J. F. \& Buunk, B. P. (1995). Affective responses to social comparison: A study among disabled individuals. British Journal of Social Psychology, 34, 279-292. 